\title{
Whole-brain dynamics in aging: disruptions in functional connectivity and the role of the rich club
}

Anira Escrichs ${ }^{1}$, Carles Biarnes ${ }^{2,3}$, Josep Garre-Olmo ${ }^{3,4,5}$, José Manuel Fernández-Real ${ }^{3,4,6}$, Rafel Ramos ${ }^{3,4,7,8}$, Reinald Pamplona ${ }^{9}$, Ramon Brugada ${ }^{3,4,10}$, Joaquin Serena ${ }^{3,4,13}$, Lluís Ramió-Torrentà ${ }^{3,4,13}$, Gabriel Coll-De-Tuero ${ }^{4,7,14}$, Luís Gallart ${ }^{15}$, Jordi Barretina ${ }^{3}$, Joan C. Vilanova ${ }^{2,3,4}$, Jordi Mayneris-Perxachs ${ }^{3,6}$, Marco Essig ${ }^{16}$, Chase R. Figley ${ }^{16}$, Salvador Pedraza ${ }^{2,3,4}$, Josep Puig ${ }^{2,3,4}$, Gustavo Deco ${ }^{1,17,18,19}$

${ }^{1}$ Computational Neuroscience Group, Center for Brain and Cognition, Department of Information and Communication Technologies, Universitat Pompeu Fabra, Barcelona, Catalonia, Spain

${ }^{2}$ Department of Radiology (IDI), Hospital Universitari de Girona Dr Josep Trueta. Girona, Spain

${ }^{3}$ Girona Biomedical Research Institute (IDIBGI), Hospital Universitari de Girona Dr Josep Trueta. Girona, Spain

${ }^{4}$ Department of Medical Sciences, School of Medicine, University of Girona, Girona, Spain

${ }^{5}$ Institut d'Assistència Sanitària, Salt (Girona) Spain

${ }^{6}$ Department of Diabetes, Endocrinology and Nutrition, IDIBGI, Hospital Universitari de Girona Dr Josep Trueta, and CIBER Fisiopatología de la Obesidad y Nutrición (CIBERobn), Girona, Spain

${ }^{7}$ Vascular Health Research Group of Girona (ISV-Girona), Institut Universitari d'Investigació en Atenció Primària Jordi Gol (IDIAP Jordi Gol). Girona, Spain

${ }^{8}$ Primary Care Services, Catalan Institute of Health (ICS), Girona, Spain

${ }^{9}$ Department of Experimental Medicine, Faculty of Medicine, University of Lleida-IRBLleida, Lleida, Spain

${ }^{10}$ Cardiovascular Genetics Center, IDIBGI, CIBER-CV, Girona, Spain

${ }^{13}$ Department of Neurology, Hospital Universitari de Girona Dr Josep Trueta, Girona, Spain

${ }^{14}$ CIBER of Epidemiology and Public Health (CIBERESP), Madrid, Spain

${ }^{15}$ Biobanc, Girona Biomedical Research Institute (IDIBGI), Girona, Spain

${ }^{16}$ Department of Radiology, University of Manitoba, Winnipeg, Canada

${ }^{17}$ Institucio Catalana de la Recerca i Estudis Avancats (ICREA), Barcelona, Catalonia, Spain

${ }^{18}$ Department of Neuropsychology, Max Planck Institute for human Cognitive and Brain Sciences, Leipzig, Germany

${ }^{19}$ Turner Institute for Brain and Mental Health, Monash University, Melbourne, VIC, Australia

Running title

Whole-brain dynamics in aging

\section{Corresponding authors}

Gustavo Deco

Computational Neuroscience Group, Center for Brain and Cognition

Department of Information and Communication Technologies, Universitat Pompeu Fabra

Barcelona, Spain

Josep Puig

Girona Biomedical Research Institute (IDIBGI)

Hospital Universitari de Girona Dr Josep Trueta

Girona, Spain 
bioRxiv preprint doi: https://doi. org/10.1101/2020 06 29.164343; this version posted June 29,2020 . The copyright holder for this preprint (which was not certified by peer review) is the author/funder, who has granted bioRxiv a license to display the preprint in perpetuity. It is made available under aCC-BY-NC-ND 4.0 International license.

\begin{abstract}
Normal aging causes disruptions in the brain that can lead to cognitive decline. Resting-state fMRI studies have found significant age-related alterations in functional connectivity across various networks. Nevertheless, most of the studies have focused mainly on static functional connectivity. Studying the dynamics of resting-state brain activity across the whole-brain functional network can provide a better characterization of age-related changes. Here we employed two data-driven whole-brain approaches based on the phase synchronization of blood-oxygen-leveldependent (BOLD) signals to analyze resting-state fMRI data from 620 subjects divided into two groups ('middleage group' ( $n=310)$; age range, 50-65 years vs. 'older group' ( $n=310)$; age range, 66-91 years). Applying the IntrinsicIgnition Framework to assess the effect of spontaneous local activation events on local-global integration, we found that the older group showed higher intrinsic ignition across the whole-brain functional network, but lower metastability. Using Leading Eigenvector Dynamics Analysis, we found that the older group showed reduced ability to access a metastable substate that closely overlaps with the so-called rich club. These findings suggest that functional whole-brain dynamics are altered in aging, probably due to a deficiency in a metastable substate that is key for efficient global communication in the brain.
\end{abstract}

Key words: aging, metastability, rich-club, resting-state fMRI, whole-brain dynamics. 
bioRxiv preprint doi: https://doi.org/10.1101/2020.06.29.164343; this version posted June 29,2020 . The copyright holder for this preprint (which was not certified by peer review) is the author/funder, who has granted bioRxiv a license to display the preprint in perpetuity. It is made available under aCC-BY-NC-ND 4.0 International license.

\section{Introduction}

Normal aging is associated with changes in the structure and function of the brain that could lead to cognitive decline and worse quality of life (Li et al., 2015). Studying the mechanisms of brain aging may identify interventions to prevent or slow age-related deterioration and improve our understanding of the mechanisms involved in neurodegenerative diseases (Ferreira and Busatto, 2013). In recent years, noninvasive resting-state functional magnetic resonance imaging (fMRI) paradigms from spontaneous blood-oxygen-level-dependent (BOLD) signals have proven useful in studying age-related changes in brain function (Ystad et al., 2011). Resting-state fMRI shows coherent spontaneous low-frequency fluctuations across brain regions and the organization of these regions into different functional networks (Zuo et al., 2010). Studies of functional connectivity have suggested age-related alterations in different resting-state networks (Raichle et al., 2001; Wang et al., 2010; Ferreira and Busatto, 2013; Grady et al., 2016), even in cognitively preserved older adults (Damoiseaux et al., 2008; Onoda et al., 2012). Other studies (Li et al., 2015; Grady et al., 2016; Fjell et al., 2017) have suggested that overactivation in functional connectivity across resting-state networks may be related to compensatory mechanisms.

Although functional connectivity studies have demonstrated reliable age-related changes, it remains unclear how brain networks cooperate to handle aging-associated declines, especially considering the effects of averaging on measurements of functional connectivity during rest (Hutchison et al., 2013). In this line, growing evidence indicates that functional connectivity among brain networks is not static over time; rather, different brain regions connect and disconnect from one another in highly complex temporal dynamics (Deco et al., 2011; Hutchison et al., 2013; Sporns, 2013; Zalesky et al., 2014; Ponce-Alvarez et al., 2015). In other words, even in the resting state, brain networks fluctuate in response to different contexts or external stimuli. Capturing statistical properties of fMRI data beyond classical static functional connectivity can facilitate the interpretation of brain functioning during the resting scan from new perspectives. This approach assumes that mental operations arise from neural communication involving coherent and flexible oscillatory activity between functional groups of neurons (Hutchison et al., 2013; Deco and Kringelbach, 2016). The term metastability (Deco and Kringelbach, 2016) refers to the temporal variability of the functional connectivity that arises from the underlying structural connectivity (the human connectome) (Sporns et al., 2005). Optimal brain function is thought to occur within a range of metastable patterns that reflects a balance between the synchronization and adaptive reconfiguration of the functional connections among the different regions that make up the structural network (Cabral et al., 2011).

Dynamic (time-varying) functional connectivity has been explored across the lifespan (Nomi et al., 2017), across different states of consciousness (Deco et al., 2017b; Escrichs et al., 2019; Lord et al., 2019), in patients with brain disorders (Puig et al., 2018), and during healthy aging (Tian et al., 2018; Nobukawa et al., 2019). One study that evaluated resting-state fMRI data from 250 subjects to examine patterns of resting-state functional connectivity over time found that dynamic connectivity patterns are consistent across groups (Abrol et al., 2016). Another study (Yin et al., 2016) found that age-related changes in the functional flexibility of the brain differ in different regions of the cerebral cortex. A recent study in 188 cognitively healthy elderly individuals (Lou et al., 2019) found that frequencyspecific brain network diversity decreased with increasing age at both the whole-brain and regional levels. Thus, exploring dynamic functional connectivity promises to enrich our knowledge of the functional organization of the brain, but little is known about changes in dynamic functional connectivity during aging. 
In this work, we explored age-related changes in dynamic functional connectivity across the whole-brain network, applying two recently developed data-driven methods based on the phase synchronization of resting-state fMRI BOLD signals to a large dataset from healthy human adults. We studied two aspects of whole-brain functional connectivity in middle-aged subjects versus older subjects: (1) the effects of spontaneously occurring local activation events on local-global integration through the intrinsic-ignition framework (Deco and Kringelbach, 2017; Deco et al., 2017b) and (2) recurrent dynamic functional connectivity patterns across time (here, referred to as metastable substates), their duration, and their probability of occurrence through Leading Eigenvector Dynamics Analysis (LEiDA) (Cabral et al., 2017).

\section{Materials and Methods}

\section{Subjects}

The study population was drawn from the 1030 subjects aged $\geq 50$ years who participated in the population-based Aging Imageomics Study (Puig et al., 2020) from whom data were collected between November 2018 and June 2019. We excluded subjects for whom the full brain imaging dataset was unavailable: those who did not undergo the complete brain imaging protocol including fMRI ( $n=23)$, those with MRI acquisition errors $(n=192)$, and those with uncorrectable motion artifacts ( $\mathrm{n}=92$; see the Preprocessing section below). Thus, the inclusion criteria were met by 723 subjects [ 310 aged $<65$ years (middle-aged group) and 413 aged $\geq 65$ years (older group)]. To homogenize the size of the samples in the two groups, we randomly selected 310 subjects from those aged $\geq 65$ years. The middleaged group comprised 310 subjects aged $<65$ years (mean age, 60.2 $\pm 3.7 \mathrm{y}$ ), and the older group comprised 310 subjects aged $\geq 65$ years (mean age, $71.8 \pm 4.5 \mathrm{y}$ ). Table 1 reports details about subjects' social and physical status. The ethics committee at the Dr. Josep Trueta University Hospital supervising the study approved the study protocol, and all subjects provided written informed consent.

\section{Image acquisition}

Images were acquired on a mobile 1.5T scanner (Vantage Elan, Toshiba Medical Systems at the beginning of the study; now Canon Medical Systems) with an 8-channel phased-array head coil with foam padding to restrict head motion and noise-cancelling headphones. Brain MRI studies included the acquisition of a high-resolution axial T1weighted sequence (number of slices $=112$; repetition time $(\mathrm{TR})=8 \mathrm{~ms}$; echo time $(\mathrm{TE})=4.5 \mathrm{~ms}$; flip angle $=15^{\circ}$; field of view $(F O V)=235 \times 235 \mathrm{~mm}$; and voxel size $=1.3 \times 1.3 \times 2.5 \mathrm{~mm}$ ) for structural imaging and a gradient echo-planar imaging $(\mathrm{EPI})$ sequence $\left(\mathrm{TR}=2500 \mathrm{~ms}\right.$; TE $=40 \mathrm{~ms}$; flip angle $=83^{\circ}$; FOV $=230 \times 230 \mathrm{~mm}$; and voxel size $=3.5 \times 3.5 \times 5$ $\mathrm{mm}$ without gap) with 122 continuous functional volumes acquired axially for 5 minutes for resting-state fMRI. Subjects were asked to keep their eyes closed, relax, remain as motionless as possible, and not fall asleep. 
bioRxiv preprint doi: https://doi.org/10.1101/2020.06.29.164343; this version posted June 29, 2020. The copyright holder for this preprint (which was not certified by peer review) is the author/funder, who has granted bioRxiv a license to display the preprint in perpetuity. It is made available under aCC-BY-NC-ND 4.0 International license.

\section{Image Preprocessing}

T1-weighted and EPI images were automatically oriented using Conn (Whitfield-Gabrieli and Nieto-Castanon, 2012). For preprocessing, we used the Data Processing Assistant for Resting-State fMRI (DPARSF) toolbox [ (Chao-Gan and Yu-Feng, 2010), www.rfmri.org/DPARSF], based on Statistical Parametric Mapping (SPM12) (http://www.fil.ion.ucl.ac.uk/spm). Preprocessing included: (1) discarding the first 5 volumes from each scan to allow for signal stabilization; (2) slice-timing correction; (3) realignment for head motion correction across different volumes; (4) co-registration of the functional image to the T1-weighted image; (5) normalization by using T1 image unified segmentation; (6) nuisance covariates regression: six parameters from the head motion correction, the white matter signal, and the cerebrospinal fluid signal using CompCor (Behzadi et al., 2007); (7) removal of the linear trend in the time series; (8) spatial normalization to the Montreal Neurological Institute standard space; (9) spatial smoothing with $6 \mathrm{~mm}$ full width at half-maximum Gaussian kernel; and (10) band-pass temporal filtering (0.01$0.025 \mathrm{~Hz}$ ). We used a cutoff of $0.25 \mathrm{~Hz}$ for the maximum detectable frequency in typical resting-state fMRI acquisitions (Yuen et al., 2019). Then, the time series were extracted using a resting-state atlas of 214 brain areas (without the cerebellum) which ensures the functional homogeneity within each brain subunit (Shen et al., 2013; Finn et al., 2015).

We excluded a total of 92 subjects for head rotation or movement ( 67 for head rotation $>2 \mathrm{~mm}$ or $2^{\circ}$ and 25 for frame-wise displacement (Jenkinson et al., 2002; Yan et al., 2013), defined as head motion > 2 standard deviations above the group average in $>25 \%$ timepoints).

\section{Phase Synchronization}

We computed the instantaneous phase of the BOLD signals between each pair of brain areas at each timepoint. First, to avoid artifacts, we band-pass filtered the BOLD time series within the narrowband $(0.04-0.07 \mathrm{~Hz})(\mathrm{Glerean}$ et al., 2012) (Figure 1.1A). Then, we obtained the analytic signal, $a(t)$, of the filtered time series of each brain area by computing the Hilbert transform (HT). The analytic signal represents a narrowband signal in the time domain as a rotating vector, calculated as $\{a(t)=A(t) \cdot \cos (\varphi(t))\}$, where $A(t)$ is the time-varying amplitude with carrier frequency expressed by the time-varying phase $\varphi(t)$. The amplitude is determined by the modulus and the phase is determined by the argument of the complex signal, $z(t),\{z(t)=a(t)+i . H T[a(t)]\}$, where $H T[a(t)]$ is the Hilbert transform of the analytical signal, $a(t)$, and $i$ is the imaginary unit (Glerean et al., 2012; Ponce-Alvarez et al., 2015; Deco et al., 2019a). Figure 1.1B shows the representation of the Hilbert BOLD phase for a brain area over time in the complex plane.

\section{Intrinsic-Ignition Framework}

To measure the effect of spontaneous local activation events on whole-brain integration, we applied the IntrinsicIgnition Framework (Deco and Kringelbach, 2017) using the phase space of the signals. This framework has been successfully applied in different resting-state fMRI studies (Deco et al., 2017b; Escrichs et al., 2019; Padilla et al., 
bioRxiv preprint doi: https://doi.org/10.1101/2020.06.29.164343; this version posted June 29, 2020. The copyright holder for this preprint (which was not certified by peer review) is the author/funder, who has granted bioRxiv a license to display the preprint in perpetuity. It is made available under aCC-BY-NC-ND 4.0 International license.

2019; Alonso-Martínez et al., 2020). This approach characterizes the spatiotemporal propagation of information by measuring the degree of integration among spontaneous occurring events across the brain over time. Figure 1.2 represents the algorithm used to obtain the ignition value of each brain area evoked by an event within a set time window. Specifically, we averaged across the events the integration evoked at each time $t$ with the time window set at 4TR. A binary event is defined by transforming the time series into z-scores, $z_{i}(t)$, and fixing a threshold, $\theta$, given by the sum of the mean and the standard deviation of the signal in each brain area, such that the binary sequence $\sigma(t)=1$ if $z_{i}(t)>\theta$ and crosses the threshold from below, and $\sigma(t)=0$ otherwise (Figure 1.2A) (Tagliazucchi et al., 2012; Deco et al., 2017b). First, we obtained the instantaneous phase in all brain areas as explained in the Phase Synchronization section above and Figure 1.1. Then, we calculated the phase lock matrix $P_{j k}(t)$, which describes the state of pair-wise phase synchronization at time $t$ between regions $j$ and $k$ as:

$$
P_{j k}(t)=\mathrm{e}^{-3\left|\varphi_{\mathrm{j}}(\mathrm{t})-\varphi_{\mathrm{k}}(\mathrm{t})\right|}
$$

, where $\varphi_{\mathrm{j}}(\mathrm{t})$ and $\varphi_{\mathrm{k}}(\mathrm{t})$ correspond to the obtained phase of the brain areas $j$ and $k$ at time $t$. Then, the integration is defined by measuring the length of largest connected component in the binarized symmetric phase lock matrix $P_{j k}(t)$ (Figure 1.2B). That is, given the fixed threshold $\theta$, the matrix is binarized such that $\left(0\right.$ if $\left|P_{j k}\right|<\theta, 1$ otherwise), and the integration value is computed as the length of the connected component considered as an adjacent graph (i.e., the largest subcomponent) (Figure 1.2C). The largest subcomponent represents the broadness of communication across the network for each driving event (Deco et al., 2015). Finally, repeating the process for each event in each brain area, the framework returns the mean integration and the standard deviation across the network. The mean integration is called ignition and it represents the spatial diversity; the standard deviation is called metastability, and it represents the variability over time for each brain area. Greater metastability in a brain area means that its activity changes more frequently across time within the network. The framework was computed across the whole-brain functional network (214 brain areas), as well as independently for eight resting-state networks: the frontoparietal, medial frontal, default-mode, subcortical, motor, visual I, visual II, and visual-association networks (Finn et al., 2015).

\section{Leading Eigenvector Dynamics Analysis (LEiDA)}

To identify differences between groups in recurrent patterns of time-varying connectivity (dynamic functional connectivity) or 'metastable-substates' across all subjects, we used Leading Eigenvector Dynamics Analysis (LEiDA) (Cabral et al., 2017), a k-means clustering analysis based on the phase synchronization of BOLD signals. First, we computed a dynamic phase coherence connectivity matrix (Deco and Kringelbach, 2016) with size NxNxT, where $\mathrm{N}=214$ (total number of brain areas), and $\mathrm{T}=117$ (total number of timepoints), using the Hilbert transform as explained above in the Phase Synchronization section. Then, we calculated the BOLD phase coherence matrix (Figure 1.3A) at time $t$ between each pair of brain areas $n$ and $p$ by computing the cosine of the phase difference as:

$$
d F C(n, p, t)=\cos (\theta(n, t)-\theta(p, t))
$$


bioRxiv preprint doi: https://doi.org/10.1101/2020.06.29.164343; this version posted June 29, 2020. The copyright holder for this preprint (which was not certified by peer review) is the author/funder, who has granted bioRxiv a license to display the preprint in perpetuity. It is made available under aCC-BY-NC-ND 4.0 International license.

Given that the Hilbert transform expresses any signal in the polar coordinate system (i.e., $\left.a_{(t)}=A(t) \cdot \cos \left(\varphi_{(t)}\right)\right)$, when the cosine function is applied, two brain areas $n$ and $p$ with similar angles at a given time $t$ will show a phase coherence near 1 (i.e., $\cos \left(0^{\circ}\right)=1$ ), whereas two brain areas that are orthogonal at a given time $t$ will show a phase coherence near zero (i.e., $\left.\cos \left(90^{\circ}\right)=0\right)($ Cabral et al., 2017; Deco et al., 2019b). Second, to characterize the dynamic functional connectivity patterns across all subjects and timepoints, we obtained a leading eigenvector $V_{1}(t)$ for each $d F C(t)$ at time $t$ by capturing the dominant functional connectivity pattern rather than the whole set of matrices. This approach allows reducing the dimensionality of the data considerably because it only considers a single $V_{1}(t)$ for each dynamic functional connectivity matrix. The $V_{1}(t)$ is an $\mathrm{Nx} 1$ vector capturing the principal orientation of the BOLD phase (showing positive or negative values) for each of the 214 brain areas (Figure 1.3B). Finally, we applied a k-means clustering algorithm using a range from $\mathrm{k}=2$ to $\mathrm{k}=7$ clusters to detect metastable substates or dynamic functional connectivity states from all the leading eigenvectors $V_{1}(t)$ across timepoints, subjects, and groups: 117 timepoints $\times 310$ subjects $\times 2$ groups $=72,540 V_{1}(t)$. We obtained $\mathrm{k}$ cluster centroids, each one as an Nx 1 vector, which represent recurrent metastable substates across all subjects. The clustering configuration that best represented the resting-state data of all 620 subjects and distinguished between the two groups was detected at $k=3$ (Figure 1.3C). We rendered the resulting cluster centroids onto a surface cortex using Surf Ice (https://www.nitrc.org/projects/surfice/). A complete description of the method can be found in Cabral et al. (2017).

\section{Statistical analysis}

Statistical analyses were done with software MATLAB version R2017a (MathWorks, Natick, MA, USA). We applied a Monte Carlo permutation method to test the results of the Intrinsic-Ignition Framework (ignition and metastability) and to test the results of the LEiDA method (probability of occurrence and duration of each metastable substate). More specifically, we randomly shuffled the labels for each pair of conditions to be tested and created two new simulated conditions (10,000 iterations). Then, we measured how many times the difference between the new simulated conditions was greater than the difference between the real conditions; in other words, we calculated the p-value of the null hypothesis that the two random distributions show a greater difference than the real conditions. Furthermore, we applied the False Discovery Rate (FDR) method (Hochberg and Benjamini, 1990) to correct for multiple comparisons when necessary.

\section{Results}

\section{Intrinsic Ignition}

We computed the Intrinsic-Ignition Framework across the whole-brain functional network and found that the mean ignition was higher in the older group than in the middle-age group $(\mathrm{p}<0.001)$ (Figure 2a). In the middle-age group, the regions with the highest intrinsic ignition belong to the visual networks, subcortical network, frontoparietal network, motor network, and medial-frontal network: the right middle occipital gyrus, right middle temporal gyrus, right lingual gyrus, fusiform gyri, left hippocampus and parahippocampal gyrus, right inferior temporal gyrus, right 
bioRxiv preprint doi: https://doi.org/10.1101/2020.06.29.164343; this version posted June 29, 2020. The copyright holder for this preprint (which was not certified by peer review) is the author/funder, who has granted bioRxiv a license to display the preprint in perpetuity. It is made available under aCC-BY-NC-ND 4.0 International license.

superior temporal gyrus, left calcarine fissure and surrounding cortex, left precentral gyrus, and right insula. By contrast, in the older group, the regions showing the highest intrinsic ignition areas belong to the visual networks, medial frontal network, and frontoparietal network: the right middle occipital, middle temporal gyrus, left fusiform gyrus, lingual gyrus, right inferior temporal gyrus, right middle frontal gyrus, calcarine fissure and surrounding cortex in both hemispheres, left superior frontal gyrus, left inferior frontal gyrus, left insula, left thalamus, and right cuneus. Table 2 shows the 20 brain areas with the highest intrinsic-ignition capability for each group.

Metastability was lower in the older group than in the middle-age group $(\mathrm{p}<0.001)$ (Figure $2 \mathrm{~b})$. In the middle-age group, the brain areas with the highest metastability belong mainly to the default-mode network, visual networks, motor network, and frontoparietal network: the parahippocampal gyri, fusiform gyri, left inferior temporal gyrus, left lingual gyrus, left hippocampus, middle temporal gyri, right inferior occipital gyrus, right precentral gyrus, and right postcentral gyrus. By contrast, in the older group, the brain areas with the highest metastability belong mainly to the motor network, subcortical network, default-mode network, medial frontal network, and visual association network: the inferior temporal gyri, left fusiform gyrus, left superior frontal gyrus, inferior frontal gyrus, right anterior cingulate and paracingulate gyri, right median cingulate gyrus, bilateral insula, right superior temporal gyrus, left rectus gyrus, bilateral Rolandic opercula, left parahippocampal gyrus, and right precentral gyrus. Table 3 shows the 20 brain areas with the highest metastability for each group.

Moreover, we computed the intrinsic ignition and metastability independently for each resting-state network. Figure 3 shows the absolute difference between the middle-age and older groups in the intrinsic-ignition values for each brain area in each network. Compared to the middle-age group, the older group had significantly increased intrinsic ignition in the frontoparietal network (FDR-corrected, $\mathrm{p}<0.001$ ) and medial frontal network (FDR-corrected, $\mathrm{p}<0.001$ ). By contrast, the middle-age group had greater intrinsic ignition in the motor network (FDR-corrected, $\mathrm{p}<0.001)$. There were no significant differences between groups in intrinsic ignition in the default-mode, subcortical, visual I, visual II, or visual-association networks. Figure 4 shows the absolute difference between the middle-age and older groups in metastability values for each brain area in each network. Compared to the middle-age group, the older group had significantly increased metastability in the frontoparietal network (FDR-corrected, $\mathrm{p}<0.01$ ) and medial frontal network (FDR-corrected, $\mathrm{p}<0.01$ ). By contrast, the middle-age group had greater metastability in the defaultmode (FDR-corrected, $\mathrm{p}<0.05$ ), subcortical (FDR-corrected, $\mathrm{p}<0.001$ ), motor (FDR-corrected, $\mathrm{p}<0.001$ ), visual association (FDR-corrected, $\mathrm{p}<0.05$ ), and visual I networks (FDR-corrected, $\mathrm{p}<0.001$ ). Only the visual II network did not differ significantly between groups.

\section{LEiDA}

Clustering across all subjects and timepoints identified three metastable substates. Figure 5A compares the probability of occurrence of each metastable substate between groups, and Figure 5B compares the duration of these substates between groups. Figure 5C shows the three metastable substates rendered onto a surface cortex. The metastable substate that had the highest probability of occurrence (the first metastable substate) closely overlaps with the state of global BOLD coherence (Cabral et al., 2017). The probability of this substate occurring was higher in the older group $[0.476 \pm 0.008$ (mean \pm standard error) vs. $0.453 \pm 0.008$ in the middle-age group, FDR-corrected 
bioRxiv preprint doi: https://doi.org/10.1101/2020.06.29.164343; this version posted June 29, 2020. The copyright holder for this preprint (which was not certified by peer review) is the author/funder, who has granted bioRxiv a license to display the preprint in perpetuity. It is made available under aCC-BY-NC-ND 4.0 International license.

$p=0.03]$, and this substate also lasted longer in the older age group [32.465 \pm 0.957 seconds vs. $30.265 \pm 0.791$ seconds in the middle-age group, $p=0.04$ ], although the difference in duration was no longer significant after FDR correction. The second metastable substate is especially interesting because it closely overlaps with the so-called rich club (Hagmann et al., 2008; van den Heuvel and Sporns, 2011; van den Heuvel et al., 2012; Sporns, 2013). In particular, this substate involved the following areas in both hemispheres: the superior frontal cortex, precuneus, insula, and subcortical areas, such as the caudate, putamen, hippocampus, and thalamus (see Figure 5D). The networks most frequently involved in this metastable substate were the subcortical network, visual network, motor network, default-mode network, and medial frontal network. The probability of this substate occurring was greater in the middle-age group [ $0.288 \pm 0.007$ vs. $0.269 \pm 0.006$ in the older group, FDR-corrected $p=0.026]$, and this substate also lasted longer in the middle-age group [16.399 \pm 0.605 seconds vs. $14.853 \pm 0.414$ seconds in the older group, FDR-corrected $p=0.01$ ). The third metastable substate was not significantly different between groups in its probability of occurrence $(p=0.35)$ or duration $(p=0.39)$.

\section{Discussion}

Interest in characterizing resting-state functional patterns during aging is growing. Understanding the underlying dynamics across the whole-brain functional network may help us better understand age-related changes. In this line, various methods have been developed to capture statistical properties of resting-state fMRI data beyond classical static functional connectivity, providing a new perspective to interpret brain functioning during the resting scan. To investigate the underlying whole-brain dynamics, we applied two data-driven whole-brain methods based on phase coherence synchronization (Deco and Kringelbach, 2017; Cabral et al., 2017) to compare intrinsic ignition, metastability, and metastable substates between middle-aged and older subjects from a large sample of healthy human adults. To characterize the spatiotemporal propagation of information, we used the Intrinsic-Ignition Framework to measure the degree of integration of spontaneously occurring events across the whole-brain during rest. Ignition values across the whole-brain functional network were higher in older subjects than in middle-aged subjects, but older subjects also had less metastability. Applying Leading Eigenvector Dynamics Analysis (LEiDA), we found differences between groups in the probability of occurrence and duration of a metastable substate involving rich-club brain areas.

Interestingly, the older group had higher intrinsic ignition across the whole-brain functional network (Figure 2a); the brain areas with the highest intrinsic-ignition values were mainly distributed across the visual networks, frontoparietal network, and medial frontal network (Figure 2a and Table 2). The mean intrinsic-ignition value reflects spatial diversity and the broadness of communication across the whole network. These results are in line with previous studies investigating the effects of aging in resting-state networks. Geerligs et al. (2015) reported increased connectivity in older adults between the visual network and somatomotor network as well as between the visual network and cingulo-opercular network. Betzel et al. (2014) found increased functional connectivity between the dorsal attention network and the salience/ventral attention networks in older adults. Similarly, Spreng et al. (2016) found increased between-network functional connectivity across the default-mode network and dorsal attention networks during both task and rest conditions. We conclude that increased functional connectivity between resting- 
bioRxiv preprint doi: https://doi.org/10.1101/2020.06.29.164343; this version posted June 29,2020 . The copyright holder for this preprint (which was not certified by peer review) is the author/funder, who has granted bioRxiv a license to display the preprint in perpetuity. It is made available under aCC-BY-NC-ND 4.0 International license.

state networks has a significant impact across the whole-brain functional network as evidenced by the level of intrinsic ignition, and that the higher intrinsic ignition in the older group may be related to compensatory mechanisms.

Metastability was higher in the middle-age group (Figure $2 \mathrm{~b}$ and Table 3 ). This finding is particularly interesting because middle-age adults showed lower intrinsic ignition across the whole-brain functional network compared to older adults, but the underlying dynamics of the middle-age adults seem to be more complex across time. Metastability characterizes the hierarchy of information processing in the brain. Thus, brain areas showing higher metastability are more relevant for the broadcasting of information than those showing lower. Greater metastability also reflects more complex brain dynamics (i.e., a more flexible switching across time), whereas lower metastability suggests a more stable system (Deco and Kringelbach, 2017; Deco et al., 2017a; Jobst et al., 2017). Our findings are in line with previous studies on the effects of aging on brain functional dynamics. For example, the decreased metastability in the older group in our study echoes recent studies that suggest deficient network modulation in the elderly (Turner and Spreng, 2015; Damoiseaux, 2017). Xia et al. (2019) found that the number of transitions between different metastable substates decreased with age, leading them to conclude that resting mind states may shift faster in young people than in older people. Similarly, variability across large-scale networks decreases linearly with aging over the lifespan (Nomi et al., 2017) and in healthy elderly subjects (Lou et al., 2019). Moreover, our findings that areas in the temporal and occipital regions were the most important for the broadcasting of information in the middleage group (Figure $2 \mathrm{~b}$ and Table 3 ) is consistent with the results of recent time-varying resting-state fMRI studies (Nomi et al., 2017; Kumral et al., 2019). Similarly, our findings that the frontal and temporal areas were more relevant in the older group (Figure 2b and Table 3) are consistent with the results of a recent EEG study that found an enhanced brain dynamics of phase synchronization in the alpha-band frequency, predominantly in frontal areas (Nobukawa et al., 2019), which the authors suggest could reflect a general change in functional connectivity dynamics during aging. Moreover, overactivation in prefrontal brain areas has been previously observed in older adults during fMRI tasks, giving rise to different theories (Cabeza, 2002; Davis et al., 2008; Reuter-Lorenz and Cappell, 2008).

We also explored intrinsic ignition and metastability across large-scale networks, computing the intrinsic-ignition framework within eight resting-state networks. In the older group, the frontoparietal and medial frontal networks showed higher ignition and metastability (Figures 3 and 4). These findings are in line with those reported by Lou et al. (2019), who found that the frontal and temporal lobes show a more dynamic pattern with increasing age. A recent meta-analysis pointed out that age-related changes in activation commonly affect the frontoparietal and default-mode networks (Li et al., 2015). The frontoparietal network serves as a flexible hub and plays a vital role in adaptive control and implementation of different responses to demands during tasks (Cole et al., 2013). The frontoparietal network is also involved in selecting relevant information from the environment (Ptak, 2012). The default-mode and frontoparietal networks are also thought to be critical in controlling global brain dynamics (Hellyer et al., 2014).

In the present study, metastability within the default-mode, subcortical, and visual-association networks was higher in the middle-age group (Figure 4). In a recent study in a large cohort of young subjects, Lee et al. (2019) reported higher metastability in lower-order resting-state networks, such as the visual network and auditory network, which are involved in specialized, mostly externally driven functions. These networks' greater metastability might reflect a greater capacity to change their functional configuration in response to diverse, rapidly changing external inputs 
bioRxiv preprint doi: https://doi.org/10.1101/2020.06.29.164343; this version posted June 29,2020 . The copyright holder for this preprint (which was not certified by peer review) is the author/funder, who has granted bioRxiv a license to display the preprint in perpetuity. It is made available under aCC-BY-NC-ND 4.0 International license.

(Power et al., 2011). By contrast, higher-order networks such as the default-mode and central executive networks are mostly involved in internal and goal-directed processing (Raichle et al., 2001; Raichle and Snyder, 2007), so it would make sense for their functional configurations to last longer. Moreover, the previously mentioned study also found that metastability was strongly associated with various indicators of higher-order cognitive ability and physical wellbeing (Lee et al., 2019).

One of the most noteworthy results in our study was the identification of a metastable substate overlapping the socalled the 'rich club' of densely interconnected nodes (Hagmann et al., 2008; van den Heuvel and Sporns, 2011; van den Heuvel et al., 2012; Sporns, 2013; Deco et al., 2017a). This substate involved the superior frontal cortex, precuneus, insula, and subcortical areas (caudate, putamen, hippocampus, and thalamus) in both hemispheres. It is thought that the rich club might also act as a gatekeeper that coordinates interactions with lower-degree regions and the emergence of different functional network configurations (van den Heuvel and Sporns, 2011). We found that the metastable substate corresponding to the rich club was less likely to occur in the older group and that when it did occur, it did so for shorter periods of time. Damoiseaux (2017) suggested that less-efficient rich-club network might be responsible for the differences in brain dynamics observed in older subjects. Our findings are in line with the hypothesis that the rich club connects different functional modules in the brain that partially overlap with different resting-state networks (Biswal et al., 1995; van den Heuvel and Sporns, 2011). Our findings regarding the lower probability of occurrence and shorter duration of this substate in the older group might be due to alterations in the intrinsic dynamics of this particular metastable substate or in any of the brain areas involved. Rich-club regions play a key role in integrating information across the brain network; consequently, damage to a brain area belonging to the rich club can affect global communication and have repercussions in multiple cognitive domains (van den Heuvel and Hulshoff Pol, 2010; Baggio et al., 2015; Deco and Kringelbach, 2017). Our results are consistent with the observation that the efficiency of the rich-club network increases during brain development in early life and decreases late in life in a manner that yields an inverted-U when plotted along the lifespan (Cao et al., 2014; Zhao et al., 2015; Damoiseaux, 2017).

Our LEiDA analysis also found that the first metastable substate, which has been related to the global signal in fMRI studies, had a higher probability of occurrence, and longer duration in the older group (although this last comparison was no longer significant after correction for multiple comparisons) (Figure 3). Like in previous resting-state fMRI studies applying LEiDA (Cabral et al., 2017; Figueroa et al., 2019; Lord et al., 2019), this anti-correlated state of global BOLD phase coherence (i.e., all BOLD phases showing negative values in the leading eigenvector) was the most prevalent. Although the significance of the global signal remains controversial, growing evidence suggests that it could contain valuable neurophysiological information and should not therefore be treated as a nuisance term (Saad et al., 2012; Liu et al., 2017). In a study with simultaneous fMRI and EEG acquisition during rest, Wong et al. (2013) found that increased EEG vigilance induced with caffeine was associated with decreased global signal amplitude and increased anti-correlation between the default-mode network and the task-positive network. Moreover, the global signal amplitude seems to increase during early sleep stages (Fukunaga et al., 2006). However, the role of the global BOLD phase coherence state remains unclear and needs further investigation (Cabral et al., 2017). 
bioRxiv preprint doi: https://doi.org/10.1101/2020.06.29.164343; this version posted June 29, 2020. The copyright holder for this preprint (which was not certified by peer review) is the author/funder, who has granted bioRxiv a license to display the preprint in perpetuity. It is made available under aCC-BY-NC-ND 4.0 International license.

This study has several limitations. Although this cross-sectional study analyzed data from a large sample of healthy human adults, it would be very instructive to explore the age-related changes in neuroimaging in the same subjects in a longitudinal study. Data-driven methods alone are insufficient to understand the mechanisms underlying the process of aging or explain the causes of the dynamic changes observed. On the other hand, brain models simulating time series have advanced our understanding of the relationship between structure and function in the brain and the potential repercussions of disrupted connectivity from injury or disease; moreover, in silico simulations open the possibility of discovering potential stimulation targets to shift patients' global brain dynamics toward a healthier state (Deco and Kringelbach, 2014; Deco et al., 2019a). One line for future studies could focus on assessing the behavioral relevance of intrinsic ignition and metastability through the aging process. Finally, although age is strongly associated with changes in functional connectivity, more studies are needed to further characterize brain functional connectivity in older adults and resolve inconsistent results due to methodological differences among studies.

In conclusion, applying two novel data-driven approaches to examine whole-brain dynamic changes, this work provides new insights into age-related brain changes. Our findings suggest that, compared to middle-aged subjects, older subjects show higher ignition but lower metastability across the whole-brain network, as well as reduced access to a dynamic functional connectivity pattern that is key for communication in the brain. These findings support the hypothesis that cognitive processing methods differ between middle-aged and older adults. Taken together, these findings suggest that functional whole-brain dynamics are altered in aging, probably due to an imbalance in a metastable substate that involves brain areas of the so-called rich club. Further investigations will surely improve our understanding of brain changes during aging.

\section{Funding}

A.E. was supported by the Catalan project Imagenoma de L'Envelliment (Aging Imageomics Study). G.D. was supported by the Spanish Ministry of Economy and Competitiveness, Spain (grant agreement number PSI201675688-P, MINECO/AEI/FEDER-EU); European Union's Horizon 2020 FET Flagship Human Brain Project (grant agreement number 785907, HBP SGA2); the Catalan Research Support, Spain (grant agreement number 2017 SGR 1545) and La Marató TV3 2017 (grant agreement 201725.33).

Acknowledgments. The Aging Imageomics Study was funded by the Government of Catalonia's Department of Health's Pla Estratègic de Recerca i Innovació en Salut (PERIS) 2016-2020 (file number, SLT002/16/00250). We also acknowledge funding from the Spanish Ministry of Science, Innovation, and Universities (RTI2018-099200-BI00, co-financed by FEDER funds from the European Union ("A way to build Europe")), and the Generalitat of Catalonia (2017SGR696) to RP. IRBLleida is a CERCA Programme/Generalitat of Catalonia. Toshiba Medical Systems (now Canon Medical Systems) provided a dedicated 1.5T MRI scanner and ancillary MRI equipment for this study. We would like to express our sincere gratitude to the subjects who participated in the Aging Imageomics Study for their valuable contribution and the study staff for coordination and data collection.

Conflict of interest. The authors declare no conflict of interest. 
bioRxiv preprint doi: https://doi org/10.1101/2020.06 29.164343; this version posted June 29,2020 . The copyright holder for this preprint (which was not certified by peer review) is the author/funder, who has granted bioRxiv a license to display the preprint in perpetuity. It is made available under aCC-BY-NC-ND 4.0 International license.

\section{References}

Abrol A, Chaze C, Damaraju E, Calhoun VD. 2016. The chronnectome: Evaluating replicability of dynamic connectivity patterns in 7500 resting fMRI datasets. In: Proc. Annu. Int. Conf. IEEE Eng. Med. Biol. Soc. EMBS. volume 2016Octob. Institute of Electrical and Electronics Engineers Inc.. p. 5571-5574. doi:10.1109/EMBC.2016.7591989.

Alonso Martínez S, Marsman JBC, Kringelbach ML, Deco G, ter Horst GJ. 2020. Reduced spatiotemporal brain dynamics are associated with increased depressive symptoms after a relationship breakup. NeuroImage Clin. 27:102299. doi:10.1016/j.nicl.2020.102299.

Baggio HC, Segura B, Junque C, de Reus MA, Sala-Llonch R, Van den Heuvel MP. 2015. Rich Club Organization and Cognitive Performance in Healthy Older Participants. J. Cogn. Neurosci. 27:1801-1810. doi:10.1162/jocn_a_00821.

Behzadi Y, Restom K, Liau J, Liu TT. 2007. A component based noise correction method (CompCor) for BOLD and perfusion based fMRI. Neuroimage 37:90-101. doi:10.1016/j.neuroimage.2007.04.042.

Betzel RF, Byrge L, He Y, Goñi J, Zuo XN, Sporns O. 2014. Changes in structural and functional connectivity among resting-state networks across the human lifespan. Neuroimage 102:345-357. doi:10.1016/j.neuroimage.2014.07.067.

Biswal B, Yetkin FZ, Haughton VM, Hyde JS, Zerrin Yetkin F, Haughton VM, Hyde JS. 1995. Functional connectivity in the motor cortex of resting human brain using echo-planar MRI. Magn. Reson. Med. 34:537-541. doi:10.1002/mrm.1910340409.

Cabeza R. 2002. Hemispheric Asymmetry Reduction in Older Adults: The HAROLD Model doi:10.1037/08827974.17.1.85.

Cabral J, Hugues E, Sporns O, Deco G. 2011. Role of local network oscillations in resting-state functional connectivity. Neuroimage 57:130-139. doi:10.1016/j.neuroimage.2011.04.010.

Cabral J, Vidaurre D, Marques P, Magalhães R, Silva Moreira P, Miguel Soares J, Deco G, Sousa N, Kringelbach ML. 2017. Cognitive performance in healthy older adults relates to spontaneous switching between states of functional connectivity during rest. Sci. Rep. 7:5135. doi:10.1038/s41598-017-05425-7.

Cao M, Wang JHH, Dai ZJJ, Cao XYY, Jiang LLL, Fan FMM, Song XWW, Xia MRR, Shu N, Dong Q, Milham MP, Castellanos FX, Zuo XNN, He Y. 2014. Topological organization of the human brain functional connectome across the lifespan. Dev. Cogn. Neurosci. 7:76-93. doi:10.1016/J.DCN.2013.11.004.

Chao-Gan Y, Yu-Feng Z. 2010. DPARSF: A MATLAB Toolbox for "Pipeline" Data Analysis of Resting-State fMRI. Front. Syst. Neurosci. 4:13. doi:10.3389/fnsys.2010.00013. 
bioRxiv preprint doi: https://doi org/10.1101/2020.06.29164343; this version posted June 29, 2020. The copyright holder for this preprint (which was not certified by peer review) is the author/funder, who has granted bioRxiv a license to display the preprint in perpetuity. It is made available under aCC-BY-NC-ND 4.0 International license.

Cole MW, Reynolds JR, Power JD, Repovs G, Anticevic A, Braver TS. 2013. Multi-task connectivity reveals flexible hubs for adaptive task control. Nat. Neurosci. 16:1348-1355. doi:10.1038/nn.3470.

Damoiseaux J, Beckmann C, Arigita ES, Barkhof F, Scheltens P, Stam C, Smith S, Rombouts S. 2008. Reduced restingstate brain activity in the "default network" in normal aging. Cereb. Cortex 18:1856-1864. doi:10.1093/cercor/bhm207.

Damoiseaux JS. 2017. Effects of aging on functional and structural brain connectivity. Neuroimage 160:32-40. doi:10.1016/J.NEUROIMAGE.2017.01.077.

Davis SW, Dennis NA, Daselaar SM, Fleck MS, Cabeza R. 2008. Que PASA? The posterior-anterior shift in aging. Cereb. Cortex 18:1201-9. doi:10.1093/cercor/bhm155.

Deco G, Jirsa VK, McIntosh AR. 2011. Emerging concepts for the dynamical organization of resting-state activity in the brain. Nat. Rev. Neurosci. 12:43-56. doi:10.1038/nrn2961.

Deco G, Kringelbach ML. 2014. Great Expectations: Using Whole-Brain Computational Connectomics for Understanding Neuropsychiatric Disorders. Neuron 84:892-905. doi:10.1016/j.neuron.2014.08.034.

Deco G, Tononi G, Boly M, Kringelbach ML. 2015. Rethinking segregation and integration: contributions of wholebrain modelling. Nat. Rev. Neurosci. 16:430-439. doi:10.1038/nrn3963.

Deco G, Kringelbach ML. 2016. Metastability and Coherence: Extending the Communication through Coherence Hypothesis Using A Whole-Brain Computational Perspective. Trends Neurosci. 39:125-135. doi:10.1016/j.tins.2016.01.001.

Deco G, Kringelbach ML. 2017. Hierarchy of Information Processing in the Brain: A Novel 'Intrinsic Ignition' Framework. Neuron 94:961-968. doi:10.1016/j.neuron.2017.03.028.

Deco G, Kringelbach ML, Jirsa VK, Ritter P. 2017. The dynamics of resting fluctuations in the brain: metastability and its dynamical cortical core. Sci. Rep. 7:3095. doi:10.1038/s41598-017-03073-5.

Deco G, Cruzat J, Cabral J, Tagliazucchi E, Laufs H, Logothetis NK, Kringelbach ML. 2019a. Awakening: Predicting external stimulation to force transitions between different brain states. Proc. Natl. Acad. Sci. 116:18088-18097. doi:10.1073/pnas.1905534116.

Deco G, Cruzat J, Kringelbach ML. 2019b. Brain songs framework used for discovering the relevant timescale of the human brain. Nat. Commun. 10. doi:10.1038/s41467-018-08186-7. 
Escrichs A, Sanjuán A, Atasoy S, López-González A, Garrido C, Càmara E, Deco G. 2019. Characterizing the Dynamical Complexity Underlying Meditation. Front. Syst. Neurosci. 13:27. doi:10.3389/fnsys.2019.00027.

Ferreira LK, Busatto GF. 2013. Resting-state functional connectivity in normal brain aging. doi:10.1016/j.neubiorev.2013.01.017.

Figueroa CA, Cabral J, Mocking RJT, Rapuano KM, van Hartevelt TJ, Deco G, Expert P, Schene AH, Kringelbach ML, Ruhé HG. 2019. Altered ability to access a clinically relevant control network in patients remitted from major depressive disorder. Hum. Brain Mapp. doi:10.1002/hbm.24559.

Finn ES, Shen X, Scheinost D, Rosenberg MD, Huang J, Chun MM, Papademetris X, Constable RT. 2015. Functional connectome fingerprinting: identifying individuals using patterns of brain connectivity. Nat. Neurosci. 18:1664-1671. doi:10.1038/nn.4135.

Fjell AM, Sneve MH, Grydeland H, Storsve AB, Walhovd KB. 2017. The Disconnected Brain and Executive Function Decline in Aging. Cereb. Cortex 27:2303-2317. doi:10.1093/cercor/bhw082.

Fukunaga M, Horovitz SG, van Gelderen P, de Zwart JA, Jansma JM, Ikonomidou VN, Chu R, Deckers RH, Leopold DA, Duyn JH. 2006. Large-amplitude, spatially correlated fluctuations in BOLD fMRI signals during extended rest and early sleep stages. Magn. Reson. Imaging 24:979-992. doi:10.1016/j.mri.2006.04.018.

Geerligs L, Renken RJ, Saliasi E, Maurits NM, Lorist MM. 2015. A Brain-Wide Study of Age-Related Changes in Functional Connectivity. Cereb. Cortex 25:1987-1999. doi:10.1093/cercor/bhu012.

Glerean E, Salmi J, Lahnakoski JM, Jääskeläinen IP, Sams M. 2012. Functional magnetic resonance imaging phase synchronization as a measure of dynamic functional connectivity. Brain Connect. 2:91-101. doi:10.1089/brain.2011.0068.

Grady C, Sarraf S, Saverino C, Campbell K. 2016. Age differences in the functional interactions among the default, frontoparietal control, and dorsal attention networks. Neurobiol. Aging 41:159-172. doi:10.1016/J.NEUROBIOLAGING.2016.02.020.

Hagmann P, Cammoun L, Gigandet X, Meuli R, Honey CJ, Wedeen VJ, Sporns O. 2008. Mapping the structural core of human cerebral cortex. PLoS Biol. 6:e159. doi:10.1371/journal.pbio.0060159.

Hellyer PJ, Shanahan M, Scott G, Wise RJ, Sharp DJ, Leech R. 2014. The control of global brain dynamics: Opposing actions of frontoparietal control and default mode networks on attention. J. Neurosci. 34:451-461. doi:10.1523/JNEUROSCI.1853-13.2014. 
bioRxiv preprint doi: https://doi.org/10.1101/2020.06.29.164343. this version posted June 29 2020. The copyright holder for this preprint (which was not certified by peer review) is the author/funder, who has granted bioRxiv a license to display the preprint in perpetuity. It is made available under aCC-BY-NC-ND 4.0 International license.

Hochberg Y, Benjamini Y. 1990. More powerful procedures for multiple significance testing. Stat. Med. 9:811-818. doi:10.1002/sim.4780090710.

Hutchison RM, Womelsdorf T, Allen EA, Bandettini PA, Calhoun VD, Corbetta M, Della Penna S, Duyn JH, Glover GH, Gonzalez-Castillo J, Handwerker DA, Keilholz S, Kiviniemi V, Leopold DA, de Pasquale F, Sporns O, Walter M, Chang C. 2013. Dynamic functional connectivity: Promise, issues, and interpretations. Neuroimage 80:360-378. doi:10.1016/j.neuroimage.2013.05.079.NIHMS150003.

Jenkinson M, Bannister P, Brady M, Smith S. 2002. Improved Optimization for the Robust and Accurate Linear Registration and Motion Correction of Brain Images. Neuroimage 17:825-841. doi:10.1006/nimg.2002.1132.

Jobst BM, Hindriks R, Laufs H, Tagliazucchi E, Hahn G, Ponce-Alvarez A, Stevner ABA, Kringelbach ML, Deco G. 2017. Increased Stability and Breakdown of Brain Effective Connectivity During Slow-Wave Sleep: Mechanistic Insights from Whole-Brain Computational Modelling. Sci. Rep. 7:4634. doi:10.1038/s41598-017-04522-x.

Kumral D, Şansal F, Cesnaite E, Mahjoory K, Al E, Gaebler M, Nikulin V, Villringer A. 2019. BOLD and EEG signal variability at rest differently relate to aging in the human brain. Neuroimage:116373 doi:10.1016/j.neuroimage.2019.116373.

Lee WH, Moser DA, Ing A, Doucet GE, Frangou S. 2019. Behavioral and Health Correlates of Resting-State Metastability in the Human Connectome Project. Brain Topogr. 32:80-86. doi:10.1007/s10548-018-0672-5.

Li HJ, Hou XH, Liu HH, Yue CL, Lu GM, Zuo XN. 2015. Putting age-related task activation into large-scale brain networks: A meta-analysis of 114 fMRI studies on healthy aging. doi:10.1016/j.neubiorev.2015.08.013.

Liu TT, Nalci A, Falahpour M. 2017. The global signal in fMRI: Nuisance or Information? Neuroimage 150:213-229. doi:10.1016/J.NEUROIMAGE.2017.02.036.

Lord LD, Expert P, Atasoy S, Roseman L, Rapuano K, Lambiotte R, Nutt DJ, Deco G, CarhartHarris RL, Kringelbach ML, Cabral J. 2019. Dynamical exploration of the repertoire of brain networks at rest is modulated by psilocybin. Neuroimage doi:10.1016/J.NEUROIMAGE.2019.05.060.

Lou W, Wang D, Wong A, Chu WC, Mok VC, Shi L. 2019. Frequency-specific age-related decreased brain network diversity in cognitively healthy elderly: A whole-brain data-driven analysis. Hum. Brain Mapp. 40:340-351. doi:10.1002/hbm.24376.

Nobukawa S, Kikuchi M, Takahashi T. 2019. Changes in functional connectivity dynamics with aging: A dynamical phase synchronization approach. Neuroimage 188:357-368. doi:10.1016/J.NEUROIMAGE.2018.12.008. 
Nomi JS, Bolt TS, Chiemeka Ezie CE, Uddin LQ, Heller AS. 2017. Moment-to-moment BOLD signal variability reflects regional changes in neural flexibility across the lifespan. J. Neurosci. 37:5539-5548. doi:10.1523/JNEUROSCI.340816.2017 .

Onoda K, Ishihara M, Yamaguchi S. 2012. Decreased functional connectivity by aging is associated with cognitive decline. J. Cogn. Neurosci. 24:2186-2198. doi:10.1162/jocn a 00269.

Padilla N, Saenger VM, Van Hartevelt TJ, Fernandes HM, Lennartsson F, Andersson JLR, Kringelbach M, Deco G, Åden U. 2020. Breakdown of Whole-brain Dynamics in Preterm-born Children. Cereb. Cortex 30:1159-1170. doi:10.1093/cercor/bhz156.

Ponce-Alvarez A, Deco G, Hagmann P, Romani GL, Mantini D, Corbetta M. 2015. Resting-State Temporal Synchronization Networks Emerge from Connectivity Topology and Heterogeneity. PLOS Comput. Biol. 11:e1004100. doi:10.1371/journal.pcbi.1004100.

Power JD, Cohen AL, Nelson SM, Wig GS, Barnes KA, Church JA, Vogel AC, Laumann TO, Miezin FM, Schlaggar BL, Petersen SE. 2011. Functional Network Organization of the Human Brain. Neuron 72:665-678. doi:10.1016/j.neuron.2011.09.006.

Ptak R. 2012. The frontoparietal attention network of the human brain: Action, saliency, and a priority map of the environment. doi:10.1177/1073858411409051.

Puig J, Biarnes C, Pedraza S, Vilanova JC, Pamplona R, Fernández-Real JM, Brugada R, Ramos R, Coll-de Tuero G, Calvo-Perxas L, Serena J, Ramió-Torrentà L, Gich J, Gallart L, Portero-Otin M, Alberich-Bayarri A, Jimenez-Pastor A, Camacho-Ramos E, Mayneris-Perxachs J, Pineda V, Font R, Prats-Puig A, Gacto ML, Deco G, Escrichs A, Clotet B, Paredes R, Negredo E, Triaire B, Rodríguez M, Heredia-Escámez A, Coronado R, de Graaf W, Prevost V, Mitulescu A, Daunis-i Estadella P, Thió-Henestrosa S, Miralles F, Ribas-Ripoll V, Puig-Domingo M, Essig M, Figley CR, Figley TD, Albensi B, Ashraf A, Reiber JH, Schifitto G, Md Nasir U, LeivaSalinas C, Wintermark M, Nael K, Vilalta-Franch J, Barretina J, Garre-Olmo J. 2020. The aging imageomics study: rationale, design and baseline characteristics of the study population. Mech. Ageing Dev. 111257 doi:10.1016/j.mad.2020.111257.

Puig J, Blasco G, Alberich-Bayarri A, Schlaug G, Deco G, Biarnes C, Navas-Martí M, Rivero M, Gich J, Figueras J, Torres C, Daunis-i Estadella P, Oramas-Requejo CL, Serena J, Stinear CM, Kuceyeski A, Soriano-Mas C, Thomalla G, Essig M, Figley CR, Menon B, Demchuk A, Nael K, Wintermark M, Liebeskind DS, Pedraza S. 2018. Resting-State Functional Connectivity Magnetic Resonance Imaging and Outcome After Acute Stroke. Stroke 49:2353-2360. doi:10.1161/STROKEAHA.118.021319.

Raichle ME, MacLeod AM, Snyder AZ, Powers WJ, Gusnard DA, Shulman GL. 2001. A default mode of brain function. Proc. Natl. Acad. Sci. U. S. A. 98:676-82. doi:10.1073/pnas.98.2.676.0402594v3. 
bioRxiv preprint doi: https://doi org/10.1101/2020.06 29.164343; this version posted June 29,2020 . The copyright holder for this preprint (which was not certified by peer review) is the author/funder, who has granted bioRxiv a license to display the preprint in perpetuity. It is made available under aCC-BY-NC-ND 4.0 International license.

Raichle ME, Snyder AZ. 2007. A default mode of brain function: A brief history of an evolving idea. doi:10.1016/j.neuroimage.2007.02.041.

Reuter-Lorenz PA, Cappell KA. 2008. Neurocognitive Aging and the Compensation Hypothesis. Curr. Dir. Psychol. Sci. 17:177-182. doi:10.1111/j.1467-8721.2008.00570.x.

Saad ZS, Gotts SJ, Murphy K, Chen G, Jo HJ, Martin A, Cox RW. 2012. Trouble at Rest: How Correlation Patterns and Group Differences Become Distorted After Global Signal Regression. Brain Connect. 2:25-32. doi:10.1089/brain.2012.0080.

Shen X, Tokoglu F, Papademetris X, Constable RT. 2013. Groupwise whole-brain parcellation from resting-state fMRI data for network node identification. Neuroimage 82:403-415. doi:10.1016/j.neuroimage.2013.05.081.

Sporns O, Tononi G, Kötter R, O’Neill M, Young M. 2005. The Human Connectome: A Structural Description of the Human Brain. PLoS Comput. Biol. 1:e42. doi:10.1371/journal.pcbi.0010042.

Sporns O. 2013. Network attributes for segregation and integration in the human brain. Curr. Opin. Neurobiol. 23:162171. doi:10.1016/J.CONB.2012.11.015.

Spreng RN, Stevens WD, Viviano JD, Schacter DL. 2016. Attenuated anticorrelation between the default and dorsal attention networks with aging: evidence from task and rest. Neurobiol. Aging 45:149-160. doi:10.1016/j.neurobiolaging.2016.05.020.

Tagliazucchi E, Balenzuela P, Fraiman D, Chialvo DR. 2012. Criticality in large-scale brain FMRI dynamics unveiled by a novel point process analysis. Front. Physiol. 3:15. doi:10.3389/fphys.2012.00015.

Tian L, Li Q, Wang C, Yu J. 2018. Changes in dynamic functional connections with aging. Neuroimage 172:31-39. doi:10.1016/J.NEUROIMAGE.2018.01.040.

Tomasi D, Volkow ND. 2012. Aging and functional brain networks. Mol. Psychiatry 17:549-558. doi:10.1038/mp.2011.81.

Turner GR, Spreng RN. 2015. Prefrontal Engagement and Reduced Default Network Suppression Co-occur and Are Dynamically Coupled in older Adults: The Default-Executive Coupling Hypothesis of Aging. J. Cogn. Neurosci. 27:2462-2476. doi:10.1162/jocn_a_00869.

van den Heuvel MP, Hulshoff Pol HE. 2010. Exploring the brain network: A review on resting-state fMRI functional connectivity. Eur. Neuropsychopharmacol. 20:519-534. doi:10.1016/j.euroneuro.2010.03.008. 
bioRxiv preprint doi: https://doi org/10.1101/2020.06 29 164343; this version posted June 29, 2020. The copyright holder for this preprint (which was not certified by peer review) is the author/funder, who has granted bioRxiv a license to display the preprint in perpetuity. It is made available under aCC-BY-NC-ND 4.0 International license.

van den Heuvel MP, Sporns O. 2011. Rich-club organization of the human connectome. J. Neurosci. 31:15775-86. doi:10.1523/JNEUROSCI.3539-11.2011.

van den Heuvel MP, Kahn RS, Goñi J, Sporns O. 2012. High-cost, high-capacity backbone for global brain communication. Proc. Natl. Acad. Sci. U. S. A. 109:11372-7. doi:10.1073/pnas.1203593109.

Wang L, LaViolette P, O’Keefe K, Putcha D, Bakkour A, Van Dijk KR, Pihlajamäki M, Dickerson BC, Sperling RA. 2010. Intrinsic connectivity between the hippocampus and posteromedial cortex predicts memory performance in cognitively intact older individuals. Neuroimage 51:910-917. doi:10.1016/j.neuroimage.2010.02.046.

Whitfield-Gabrieli S, Nieto-Castanon A. 2012. Conn: A Functional Connectivity Toolbox for Correlated and Anticorrelated Brain Networks. Brain Connect. 2:125-141. doi:10.1089/brain.2012.0073.

Wong CW, Olafsson V, Tal O, Liu TT. 2013. The amplitude of the resting-state fMRI global signal is related to EEG vigilance measures. Neuroimage 83:983-90. doi:10.1016/j.neuroimage.2013.07.057.

Xia Y, Chen Q, Shi L, Li M, Gong W, Chen H, Qiu J. 2019. Tracking the dynamic functional connectivity structure of the human brain across the adult lifespan. Hum. Brain Mapp. 40:717-728. doi:10.1002/hbm.24385.

Yan CG, Craddock RC, Zuo XN, Zang YF, Milham MP. 2013. Standardizing the intrinsic brain: towards robust measurement of inter-individual variation in 1000 functional connectomes. Neuroimage 80:246-62. doi:10.1016/j.neuroimage.2013.04.081.

Yin D, Liu W, Zeljic K, Wang Z, Lv Q, Fan M, Cheng W, Wang Z. 2016. Dissociable changes of frontal and parietal cortices in inherent functional flexibility across the human life span. J.Neurosci. 36:10060-10074. doi:10.1523/JNEUROSCI.1476-16.2016.

Ystad M, Hodneland E, Adolfsdottir S, Haász J, Lundervold AJ, Eichele T, Lundervold A. 2011. Cortico-striatal connectivity and cognition in normal aging: A combined DTI and resting state fMRI study. Neuroimage 55:24-31. doi:10.1016/j.neuroimage.2010.11.016.

Yuen NH, Osachoff N, Chen JJ. 2019. Intrinsic Frequencies of the Resting-State fMRI Signal: The Frequency Dependence of Functional Connectivity and the Effect of Mode Mixing. Front. Neurosci. 13:900. doi:10.3389/fnins.2019.00900.

Zalesky A, Fornito A, Cocchi L, Gollo LL, Breakspear M. 2014. Time-resolved resting-state brain networks. Proc. Natl. Acad. Sci. U. S. A. 111:10341-10346. doi:10.1073/pnas.1400181111. 
bioRxiv preprint doi: https://doi.org/10.1101/2020.06.29.164343; this version posted June 29, 2020. The copyright holder for this preprint (which was not certified by peer review) is the author/funder, who has granted bioRxiv a license to display the preprint in perpetuity. It is made available under aCC-BY-NC-ND 4.0 International license.

Zhao T, Cao M, Niu H, Zuo XN, Evans A, He Y, Dong Q, Shu N. 2015. Age-related changes in the topological organization of the white matter structural connectome across the human lifespan. Hum. Brain Mapp. 36:3777-3792. doi:10.1002/hbm.22877.

Zuo XN, Di Martino A, Kelly C, Shehzad ZE, Gee DG, Klein DF, Castellanos FX, Biswal BB, Milham MP. 2010. The oscillating brain: Complex and reliable. Neuroimage 49:1432-1445. doi:10.1016/j.neuroimage.2009.09.037. 
Table 1. Demographic and clinical characteristics

\begin{tabular}{|c|c|c|c|}
\hline & $\begin{array}{l}\text { Overall } \\
\text { sample } \\
(n=620)\end{array}$ & $\begin{array}{c}\text { Middle-age group } \\
(50-64 \text { years }) \\
(\mathrm{n}=310)\end{array}$ & $\begin{array}{c}\text { Older } \\
\text { group } \\
(\geq \text { 65years }) \\
(\mathrm{n}=310)\end{array}$ \\
\hline Sex (female), n (\%) & $307(49.5)$ & $169(54.5)$ & $138(44.5)$ \\
\hline Age, mean (SD) & $65.9(7.2)$ & $60.2(3.7)$ & $71.8(4.5)$ \\
\hline \multicolumn{4}{|l|}{ Age groups, $\mathrm{n}(\%)$} \\
\hline $50-64$ & 310 & & \\
\hline $65-91$ & 310 & & \\
\hline \multicolumn{4}{|l|}{ Education level *, n (\%) } \\
\hline No schooling & $18(2.9)$ & $2(0.7)$ & $16(5.2)$ \\
\hline Primary (ISCED 1) & $324(52.8)$ & $133(43.3)$ & $191(62.2)$ \\
\hline Secondary (ISCED 2) & $90(14.7)$ & $55(17.9)$ & $35(11.4)$ \\
\hline Professional (ISCED 3-4) & $107(17.4)$ & $67(21.8)$ & $40(13.0)$ \\
\hline University (ISCED 5-8) & $75(12.2)$ & $50(16.3)$ & $25(8.1)$ \\
\hline \multicolumn{4}{|l|}{ Body mass index **, n (\%) } \\
\hline$<18.5 \mathrm{~kg} / \mathrm{m}^{2}$ & $5(0.8)$ & $5(1.6)$ & $0(0.0)$ \\
\hline $18.5 \mathrm{~kg} / \mathrm{m}^{2}-24.9 \mathrm{~kg} / \mathrm{m}^{2}$ & $156(25.2)$ & $96(31.2)$ & $60(19.4)$ \\
\hline $25.0 \mathrm{~kg} / \mathrm{m}^{2}-29.9 \mathrm{~kg} / \mathrm{m}^{2}$ & $279(45.1)$ & $118(38.3)$ & $161(51.9)$ \\
\hline$\geq 30 \mathrm{~kg} / \mathrm{m}^{2}$ & $178(28.8)$ & $89(28.9)$ & $89(28.7)$ \\
\hline \multicolumn{4}{|l|}{ Physical activity groups (IPAQ), $\mathrm{n}(\%) \dagger$} \\
\hline High & $303(51.5)$ & $136(47.2)$ & $167(55.7)$ \\
\hline Moderate & $248(42.2)$ & $130(45.1)$ & $118(39.3)$ \\
\hline Low & $37(6.3)$ & $22(7.6)$ & $15(5.0)$ \\
\hline Weight $(\mathrm{kg})$, mean (SD) & $75.6(14.1)$ & $75.1(15.5)$ & $76.1(12.5)$ \\
\hline Height $(\mathrm{cm})$, mean $(\mathrm{SD})$ & $164(9.0)$ & $164(9.1)$ & $163(9.1)$ \\
\hline $\begin{array}{l}\text { Systolic arterial pressure }(\mathrm{mmHg}), \text { mean } \\
\text { (SD) }\end{array}$ & $138.8(19.4)$ & $135.1(19.2)$ & $142.6(18.8)$ \\
\hline $\begin{array}{l}\text { Diastolic arterial pressure }(\mathrm{mmHg}) \text {, mean } \\
\text { (SD) }\end{array}$ & $84.1(10.6)$ & $85.0(10.1)$ & $83.1(11.0)$ \\
\hline Hypertension, n (\%) \# & $289(46.9)$ & $120(38.8)$ & $169(55.0)$ \\
\hline Diabetes mellitus, n (\%) \# & $139(22.5)$ & $47(15.2)$ & $92(29.9)$ \\
\hline Dyslipidemia, n (\%) \# & $181(29.4)$ & $79(25.5)$ & $102(33.3)$ \\
\hline
\end{tabular}

* 6 missing values; $* * 2$ missing values; $† 32$ missing values; \# 4 missing values

IPAQ: International Physical Activity Questionnaire 
bioRxiv preprint doi: https://doi.org/10.1101/2020.06.29.164343; this version posted June 29, 2020. The copyright holder for this preprint (which was not certified by peer review) is the author/funder, who has granted bioRxiv a license to display the preprint in perpetuity. It is made available under aCC-BY-NC-ND 4.0 International license.

Table 2. Intrinsic ignition capability

\begin{tabular}{|c|c|c|c|c|c|}
\hline \multicolumn{3}{|c|}{ Middle-age group } & \multicolumn{3}{|c|}{ Older Group } \\
\hline $\begin{array}{l}\text { rs- } \\
\text { fMRI } \\
\text { atlas }\end{array}$ & Corresponding AAL-regions & Network & $\begin{array}{l}\text { rs- } \\
\text { fMRI } \\
\text { atlas }\end{array}$ & Corresponding AAL-regions & Network \\
\hline 74 & $\begin{array}{l}\text { 34\% Middle occipital gyrus, right [52] } \\
\text { 32\% Middle temporal gyrus, right [86] }\end{array}$ & $\begin{array}{l}\text { Visual } \\
\text { association }\end{array}$ & 74 & $\begin{array}{l}34 \% \text { Middle occipital gyrus, right [52] } \\
32 \% \text { Middle temporal gyrus, right [86] }\end{array}$ & $\begin{array}{l}\text { Visual } \\
\text { association }\end{array}$ \\
\hline 185 & 88\% Lingual gyrus, left [47] & Visual & 181 & $\begin{array}{l}40 \% \text { Fusiform gyrus, left [55] } \\
31 \% \text { Lingual gyrus, left [47] }\end{array}$ & Visual_I \\
\hline 79 & 78\% Lingual gyrus, right [48] & Visual & 173 & $63 \%$ Inferior temporal gyrus, left [89] & Frontoparietal \\
\hline 72 & $\begin{array}{l}\text { 51\% Lingual gyrus, right }[48] \\
33 \% \text { Fusiform gyrus, right }[56]\end{array}$ & Visual & 185 & 88\% Lingual gyrus, left [47] & Visual_I \\
\hline 181 & $\begin{array}{l}40 \% \text { Fusiform gyrus, left [55] } \\
31 \% \text { Lingual gyrus, left [47] }\end{array}$ & Visual & 70 & $70 \%$ Inferior temporal gyrus, right [90] & Frontoparietal \\
\hline 205 & $\begin{array}{l}\text { 43\% Parahippocampal gyrus, left [39] } \\
24 \% \text { Hippocampus, left [37] }\end{array}$ & Subcortical & 14 & $85 \%$ Middle frontal gyrus, right [8] & Frontoparietal \\
\hline 69 & $\begin{array}{l}51 \% \text { Inferior temporal gyrus, right }[90] \\
47 \% \text { Middle temporal gyrus, right }[86]\end{array}$ & $\begin{array}{c}\text { Visual } \\
\text { association }\end{array}$ & 53 & $\begin{array}{l}45 \% \text { Temporal pole: superior, right }[84] \\
34 \% \text { Temporal pole: middle temporal, right [88] }\end{array}$ & Medialfrontal \\
\hline 70 & $70 \%$ Inferior temporal gyrus, right $[90]$ & Frontoparietal & 69 & $\begin{array}{l}51 \% \text { Inferior temporal gyrus, right [90] } \\
47 \% \text { Middle temporal gyrus, right [86] }\end{array}$ & $\begin{array}{l}\text { Visual } \\
\text { association }\end{array}$ \\
\hline 61 & $\begin{array}{l}50 \% \text { Superior temporal gyrus, right [82] } \\
28 \% \text { Rolandic operculum, right }[18]\end{array}$ & Motor & 187 & $\begin{array}{l}38 \% \text { Lingual gyrus, left [47] } \\
20 \% \text { Calcarine fissure and surrounding cortex, left [43] }\end{array}$ & Visual_II \\
\hline 189 & $\begin{array}{l}67 \% \text { Calcarine fissure and surrounding cortex, } \\
\text { left [43] }\end{array}$ & Visual_I & 127 & $\begin{array}{l}46 \% \text { Inferior frontal gyrus, orbital part, left [15] } \\
36 \% \text { Insula, left [29] }\end{array}$ & Medialfrontal \\
\hline 173 & 63\% Inferior temporal gyrus, left [89] & Frontoparietal & 166 & $82 \%$ Middle temporal gyrus, left [85] & Medialfrontal \\
\hline 183 & $\begin{array}{l}\text { 41\% Middle temporal gyrus, left [85] } \\
35 \% \text { Middle occipital gyrus, left [51] }\end{array}$ & $\begin{array}{l}\text { Visual } \\
\text { association }\end{array}$ & 180 & $\begin{array}{l}49 \% \text { Inferior occipital gyrus, left [53] } \\
33 \% \text { Fusiform gyrus, left [55] }\end{array}$ & $\begin{array}{l}\text { Visual } \\
\text { association }\end{array}$ \\
\hline 36 & $\begin{array}{l}52 \% \text { Insula, right [30] } \\
36 \% \text { Inferior frontal gyrus, orbital, right [16] }\end{array}$ & Subcortical & 189 & $67 \%$ Calcarine fissure and surrounding cortex, left [43] & Visual_I \\
\hline 149 & $66 \%$ Superior parietal gyrus, left [59] & $\begin{array}{l}\text { Visual } \\
\text { association }\end{array}$ & 80 & $\begin{array}{l}39 \% \text { Calcarine fissure and surrounding cortex, right } \\
\text { [44] } \\
27 \% \text { Cuneus, right }[46]\end{array}$ & Visual_I \\
\hline 123 & 84\% Middle frontal gyrus, left [7] & Medial frontal & 76 & $\begin{array}{l}48 \% \text { Lingual gyrus, right }[48] \\
17 \% \text { Fusiform gyrus, right }[56]\end{array}$ & Visual_II \\
\hline 139 & $81 \%$ Precentral gyrus, left [1] & Medial frontal & 12 & $\begin{array}{l}52 \% \text { Superior frontal gyrus, dorsolateral, right [4] } \\
41 \% \text { Superior frontal gyrus, medial, right [24] }\end{array}$ & Medialfrontal \\
\hline 179 & $\begin{array}{l}57 \% \text { Lingual gyrus, left [47] } \\
21 \% \text { Calcarine fissure and surrounding cortex, } \\
\text { left [43] }\end{array}$ & Visual_I & 179 & $\begin{array}{l}57 \% \text { Lingual gyrus, left [47] } \\
21 \% \text { Calcarine fissure and surrounding cortex, left [43] }\end{array}$ & Visual_I \\
\hline 53 & $\begin{array}{l}\text { 45\% Temporal pole: superior, right }[84] \\
34 \% \text { Temporal pole: middle temporal, right }[88]\end{array}$ & Medial frontal & 212 & $\begin{array}{l}46 \% \text { Thalamus, left [77] } \\
1 \% \text { Lingual gyrus, left [47] }\end{array}$ & Subcortical \\
\hline 162 & $\begin{array}{l}54 \% \text { Temporal pole: superior temporal gyrus, } \\
\text { left [83] } \\
27 \% \text { Superior temporal gyrus, left [81] }\end{array}$ & Motor & 183 & $\begin{array}{l}\text { 41\% Middle temporal gyrus, left [85] } \\
35 \% \text { Middle occipital gyrus, left [51] }\end{array}$ & $\begin{array}{l}\text { Visual } \\
\text { association }\end{array}$ \\
\hline 63 & $\begin{array}{l}52 \% \text { Superior temporal gyrus, right }[82] \\
48 \% \text { Middle temporal gyrus, right }[86]\end{array}$ & Motor & 79 & $78 \%$ Lingual gyrus, right $[48]$ & Visual_I \\
\hline
\end{tabular}


bioRxiv preprint doi: https://doi.org/10.1101/2020.06.29.164343; this version posted June 29, 2020. The copyright holder for this preprint (which was not certified by peer review) is the author/funder, who has granted bioRxiv a license to display the preprint in perpetuity. It is made available under aCC-BY-NC-ND 4.0 International license.

Table 3. Metastability

\begin{tabular}{|c|c|c|c|c|c|}
\hline \multicolumn{3}{|c|}{ Middle-age group } & \multicolumn{3}{|c|}{ Older Group } \\
\hline \begin{tabular}{l|l} 
rs- \\
fMRI \\
atlas
\end{tabular} & Corresponding AAL-regions & Network & $\begin{array}{l}\text { rs- } \\
\text { fMRI } \\
\text { atlas }\end{array}$ & Corresponding AAL-regions & Network \\
\hline 96 & $\begin{array}{l}60 \% \text { Parahippocampal gyrus, right [40] } \\
28 \% \text { Fusiform gyrus, right [56] }\end{array}$ & Default mode & 169 & $\begin{array}{l}46 \% \text { Inferior temporal gyrus, left [89] } \\
41 \% \text { Fusiform gyrus, left [55] }\end{array}$ & Motor \\
\hline 59 & $\begin{array}{l}55 \% \text { Fusiform gyrus, right [56] } \\
41 \% \text { Inferior temporal gyrus, right [90] }\end{array}$ & $\begin{array}{l}\text { Visual } \\
\text { association }\end{array}$ & 15 & $\begin{array}{l}56 \% \text { Median cingulate and paracingulate gyri, right [34] } \\
26 \% \text { Anterior cingulate and paracingulate gyri, right [32] }\end{array}$ & Subcortical \\
\hline 187 & $\begin{array}{l}38 \% \text { Lingual gyrus, left [47] } \\
20 \% \text { Calcarine fissure and surrounding cortex [43] }\end{array}$ & Visual_II & 206 & $\begin{array}{l}\text { 55\% Fusiform gyrus, left [55] } \\
\text { 32\% Parahippocampal gyrus, left [39] }\end{array}$ & Subcortical \\
\hline 161 & $\begin{array}{l}\text { 57\% Temporal pole: middle temporal gyrus, left } \\
\text { [87] } \\
25 \% \text { Middle temporal gyrus, left [85] }\end{array}$ & $\begin{array}{l}\text { Medial } \\
\text { frontal }\end{array}$ & 108 & $\begin{array}{l}33 \% \text { Anterior cingulate and paracingulate gyri, left [31] } \\
23 \% \text { Rectus gyrus, left [27] }\end{array}$ & $\begin{array}{l}\text { Default } \\
\text { mode }\end{array}$ \\
\hline 70 & $70 \%$ Inferior temporal gyrus, right $[90]$ & Frontoparietal & 109 & $\begin{array}{l}51 \% \text { Inferior frontal gyrus, orbital part, left [15] } \\
31 \% \text { Superior frontal gyrus, orbital part, left [5] }\end{array}$ & Subcortical \\
\hline 71 & $\begin{array}{l}48 \% \text { Fusiform gyrus, right [56] } \\
29 \% \text { Inferior temporal gyrus, right [90] }\end{array}$ & $\begin{array}{l}\text { Visual } \\
\text { association }\end{array}$ & 16 & $\begin{array}{l}45 \% \text { Inferior frontal gyrus, triangular part, right [14] } \\
28 \% \text { Inferior frontal gyrus, orbital, right [16] }\end{array}$ & Medialfrontal \\
\hline 180 & $\begin{array}{l}\text { 49\% Inferior occipital gyrus, left [53] } \\
33 \% \text { Fusiform gyrus, left [55] }\end{array}$ & $\begin{array}{c}\text { Visual } \\
\text { association }\end{array}$ & 88 & $42 \%$ Median cingulate and paracingulate gyri, right [34] & Subcortical \\
\hline 188 & $\begin{array}{l}25 \% \text { Inferior occipital gyrus, left [53] } \\
23 \% \text { Lingual gyrus, left [47] }\end{array}$ & Visual_II & 57 & $67 \%$ Inferior temporal gyrus, right $[90]$ & Medialfrontal \\
\hline 172 & $71 \%$ Fusiform gyrus, left [55] & Visual_I & 18 & $\begin{array}{l}59 \% \text { Inferior frontal gyrus, orbital, right [16] } \\
20 \% \text { Insula, right [30] }\end{array}$ & Subcortical \\
\hline 27 & $81 \%$ Precentral gyrus, right [2] & Motor & 112 & $\begin{array}{l}54 \% \text { Superior frontal gyrus, medial orbital, left [25] } \\
31 \% \text { Anterior cingulate and paracingulate gyri, left [31] }\end{array}$ & Default mode \\
\hline 45 & $\begin{array}{l}47 \% \text { Supramarginal gyrus, right }[64] \\
35 \% \text { Postcentral gyrus, right [58] }\end{array}$ & Motor & 174 & $\begin{array}{l}58 \% \text { Fusiform gyrus, left [55] } \\
36 \% \text { Inferior temporal gyrus, left [89] }\end{array}$ & $\begin{array}{c}\text { Visual } \\
\text { association }\end{array}$ \\
\hline 206 & $\begin{array}{l}\text { 55\% Fusiform gyrus, left [55] } \\
32 \% \text { Parahippocampal gyrus, left [39] }\end{array}$ & Subcortical & 142 & $\begin{array}{l}59 \% \text { Insula, left [29] } \\
23 \% \text { Rolandic operculum, left [17] }\end{array}$ & Motor \\
\hline 177 & 73\% Middle occipital gyrus, left [51] & Default mode & 175 & $65 \%$ Inferior temporal gyrus, left [89] & $\begin{array}{c}\text { Visual } \\
\text { association }\end{array}$ \\
\hline 53 & $\begin{array}{l}45 \% \text { Temporal pole: superior, right }[84] \\
34 \% \text { Temporal pole: middle temporal, right [88] }\end{array}$ & $\begin{array}{l}\text { Medial } \\
\text { frontal }\end{array}$ & 111 & $62 \%$ Rectus gyrus, left [27] & $\begin{array}{l}\text { Medial } \\
\text { frontal }\end{array}$ \\
\hline 81 & $\begin{array}{l}59 \% \text { Inferior occipital gyrus, right [54] } \\
23 \% \text { Lingual gyrus, right [48] }\end{array}$ & Visual_II & 122 & $\begin{array}{l}44 \% \text { Superior frontal gyrus, medial, left [23] } \\
43 \% \text { Superior frontal gyrus, dorsolateral, left [3] }\end{array}$ & $\begin{array}{l}\text { Medial } \\
\text { frontal }\end{array}$ \\
\hline 204 & $\begin{array}{l}46 \% \text { Hippocampus, left [37] } \\
19 \% \text { Inferior temporal gyrus, left [89] }\end{array}$ & Subcortical & 46 & $\begin{array}{l}\text { 53\% Superior temporal gyrus, right [82] } \\
37 \% \text { Supramarginal gyrus, right [64] }\end{array}$ & Motor \\
\hline 175 & $65 \%$ Inferior temporal gyrus, left [89] & $\begin{array}{c}\text { Visual } \\
\text { association }\end{array}$ & 71 & $\begin{array}{l}48 \% \text { Fusiform gyrus, right }[56] \\
29 \% \text { Inferior temporal gyrus, right [90] }\end{array}$ & $\begin{array}{l}\text { Visual } \\
\text { association }\end{array}$ \\
\hline 173 & $63 \%$ Inferior temporal gyrus, left [89] & Frontoparietal & 61 & $\begin{array}{l}50 \% \text { Superior temporal gyrus, right }[82] \\
28 \% \text { Rolandic operculum, right }[18]\end{array}$ & Motor \\
\hline 97 & 67\% Parahippocampal gyrus, right [40] & Motor & 31 & $\begin{array}{l}52 \% \text { Precentral gyrus, right [2] } \\
22 \% \text { Inferior frontal gyrus, opercular part, right [12] }\end{array}$ & Frontoparietal \\
\hline 203 & $\begin{array}{l}\text { 55\% Hippocampus, left [37] } \\
13 \% \text { Parahippocampal gyrus, left [39] }\end{array}$ & Subcortical & 55 & $67 \%$ Inferior temporal gyrus, right [90] & Frontoparietal \\
\hline
\end{tabular}


bioRxiv preprint doi: https:/doi.org/10.1101/2020.06.29.164343: this version posted June 29,2020 . The copyright holder for this preprint (which was not certified by peer review) is the author/funder, who has granted bioRxiv a license to display the preprint in perpetuity. It is made available under aCC-BY-NC-ND 4.0 International license.

Table 4. Cluster centroids of the significant metastable substate

\begin{tabular}{|c|c|c|c|}
\hline BOLD phase & $\begin{array}{l}\text { rs-fMRI } \\
\text { atlas }\end{array}$ & Corresponding AAL-regions & Network \\
\hline 0.03165 & 37 & $34 \%$ Insula, right [30] / 22\% Lenticular nucleus, putamen, right [74] & Motor \\
\hline 0.03151 & 201 & 42\% Hippocampus, left [37] / 5\% Thalamus, left [77] & Subcortical \\
\hline 0.02814 & 144 & $34 \%$ Insula, left [29] / 18\% Superior temporal gyrus, left [81] & Motor \\
\hline 0.02683 & 211 & 84\% Lenticular nucleus, putamen, left [73] & Subcortical \\
\hline 0.02653 & 103 & $84 \%$ Lenticular nucleus, putamen, right [74] & Subcortical \\
\hline 0.02534 & 87 & $\begin{array}{l}\text { 44\% Calcarine fissure and surrounding cortex, right [44] / 6\% Lingual gyrus, right } \\
{[48]}\end{array}$ & Visual_I \\
\hline 0.02502 & 65 & $64 \%$ Middle temporal gyrus, right & Medial frontal \\
\hline 0.02415 & 108 & $33 \%$ Anterior cingulate and paracingulate gyri, left [31] / 23\% Rectus gyrus, left [27] & Default mode \\
\hline 0.02271 & 102 & $57 \%$ Caudate nucleus, right [72] / 11\% Olfactory cortex, right [22] & Subcortical \\
\hline 0.02262 & 143 & $81 \%$ Insula, left [29] & Subcortical \\
\hline 0.02246 & 212 & $46 \%$ Thalamus, left [77] / 1\% Lingual gyrus, left [47] & Subcortical \\
\hline 0.02191 & 165 & $62 \%$ Middle temporal gyrus, left [85] & Motor \\
\hline 0.02145 & 93 & 50\% Hippocampus right [38] / 9\% Parahippocampal right [40] & Subcortical \\
\hline 0.02133 & 190 & $59 \%$ Calcarine fissure and surrounding cortex [43] / 7\% Lingual gyrus, left [47] & Visual_I \\
\hline 0.02053 & 50 & $87 \%$ Middle temporal gyrus, right [86] & Default mode \\
\hline 0.02036 & 105 & $36 \%$ Thalamus, right [78] / 9\% Lingual gyrus, right [48] & Subcortical \\
\hline 0.01982 & 98 & $49 \%$ Lingual gyrus, right [48] / 23\% Precuneus, right [68] & Visual_I \\
\hline 0.01935 & 209 & $28 \%$ Caudate nucleus, left [71] / 15\% Olfactory cortex, left [21] & Subcortical \\
\hline 0.01870 & 82 & $76 \%$ Calcarine fissure and surrounding cortex, right $[44]$ & Visual_I \\
\hline 0.01771 & 54 & $58 \%$ Middle temporal gyrus, right [86] / 32\% Superior temporal gyrus, right [82] & Medial frontal \\
\hline
\end{tabular}


1) BOLD Phase

A

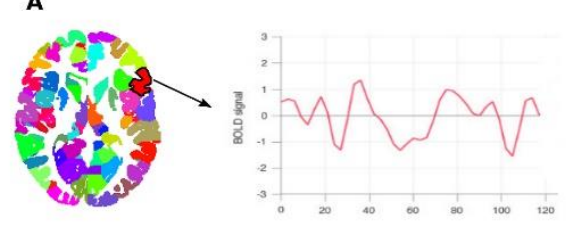

B

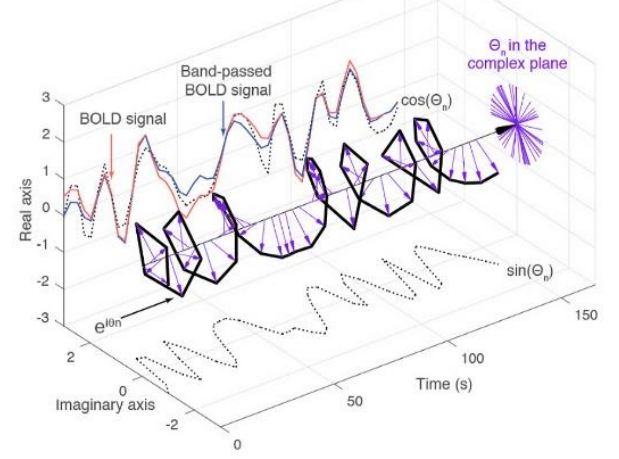

2) Ignition

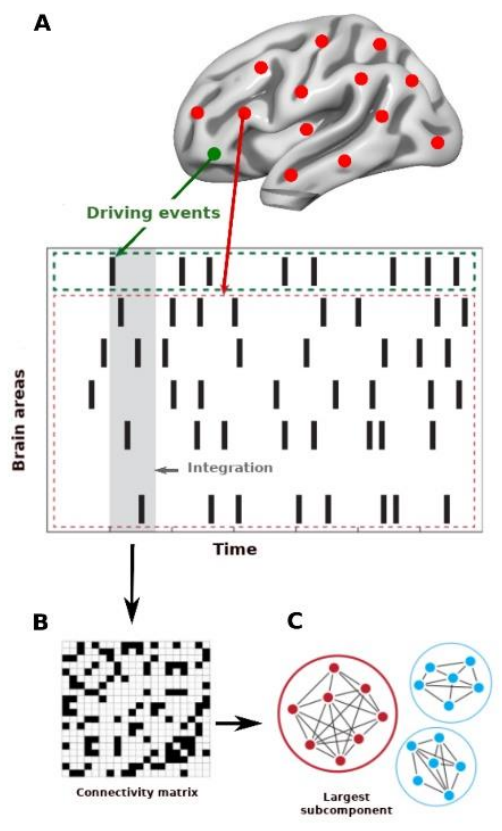

3) LEIDA

A
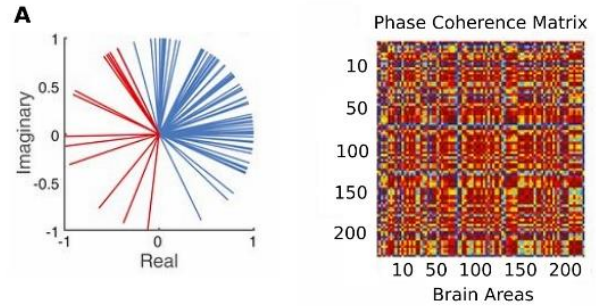

B
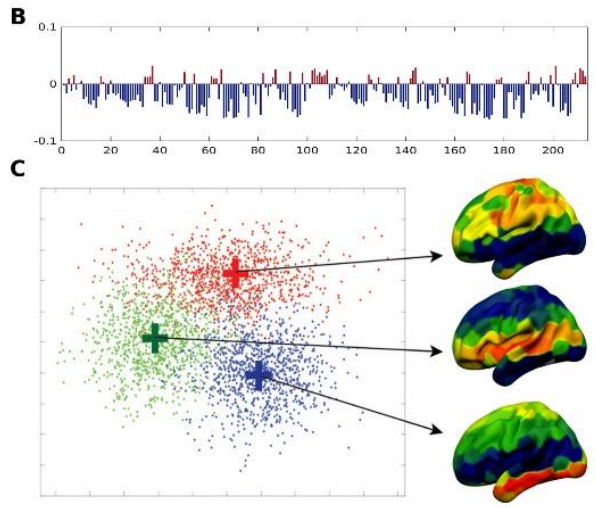

Figure 1: Methods. We applied two data-driven whole-brain methods based on phase synchronization of the BOLD signals. (1) For each of the 214 brain areas, we extracted the BOLD time series and computed the phase space of the BOLD signal. (1A) Specifically, we obtained the time series for each brain area using a resting-state atlas (Shen et al., 2013). (1B) Then, we measured the phase space of the BOLD signal by using the Hilbert transform for each brain area. The BOLD signal (red) was band-pass filtered between 0.04 and $0.07 \mathrm{~Hz}$ (blue) and converted with the Hilbert transform into an analytical signal represented by its instantaneous amplitude $\mathrm{A}(\mathrm{t})$ and its phase $\varphi$ (with real and imaginary components). The phase dynamics can be represented in the complex plane as $\mathrm{e}^{\mathrm{i} \varphi}$ (black bold line), the real part as $\cos \varphi$ (black dotted line), and the imaginary part as $\sin \varphi$ (black dotted line). The purple arrows represent the Hilbert phases at each TR. (2) Measuring intrinsic ignition. (2A) Events were captured by applying a threshold method (Tagliazucchi et al., 2012) (see green area). For each event evoked, the activity in the rest of the network (see red stippled area) was measured in the 4TR time window (gray area). (2B) A binarized phase lock matrix was obtained from the time window. (2C) From this phase lock matrix, we obtained the integration by calculating the largest subcomponent (i.e., by applying the global integration measure (Deco et al., 2015, 2017b)). Repeating the process for each driving event, we obtained the ignition and metastability of the intrinsic-driven integration for each brain area across the whole-brain network. (3) Finally, we applied the Leading Eigenvector Dynamics Analysis (LEiDA) to characterize differences between groups in dynamic functional connectivity patterns or metastable substates. (3A) The left panel shows the BOLD phases in all 214 brain areas represented in the complex plane. The right panel shows the phase coherence matrix between each pair of brain areas. (3B) The leading eigenvector V1(t) from this matrix was extracted. (3C) We applied a k-means clustering algorithm to detect the metastable substates from all the leading eigenvectors, across timepoints, number of subjects, and groups. Figure adapted from (Deco and Kringelbach, 2017, Deco et al., 2019a). 
bioRxiv preprint doi: https://doi.org/10.1101/2020.06.29.164343; this version posted June 29, 2020. The copyright holder for this preprint (which was not certified by peer review) is the author/funder, who has granted bioRxiv a license to display the preprint in perpetuity. It is made available under aCC-BY-NC-ND 4.0 International license.

a)
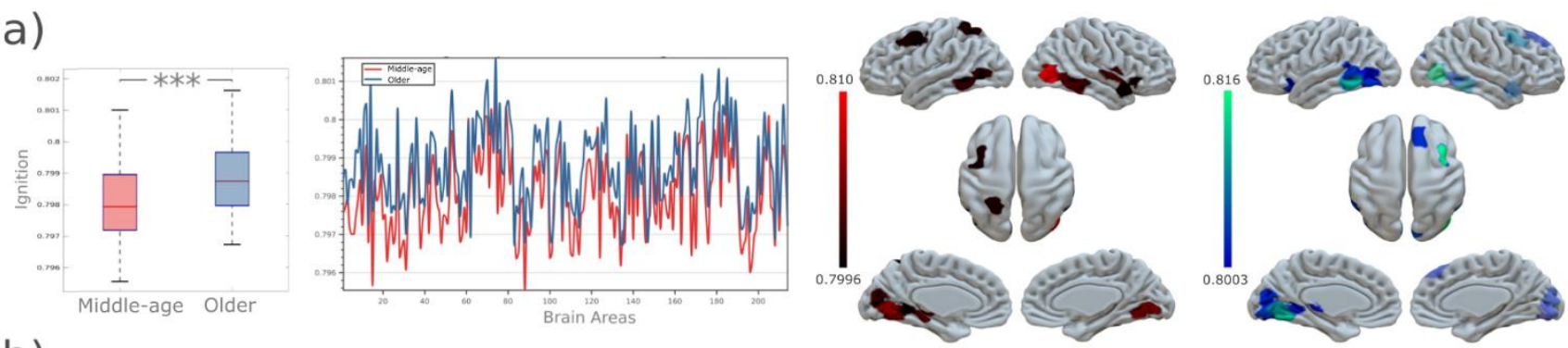

b)
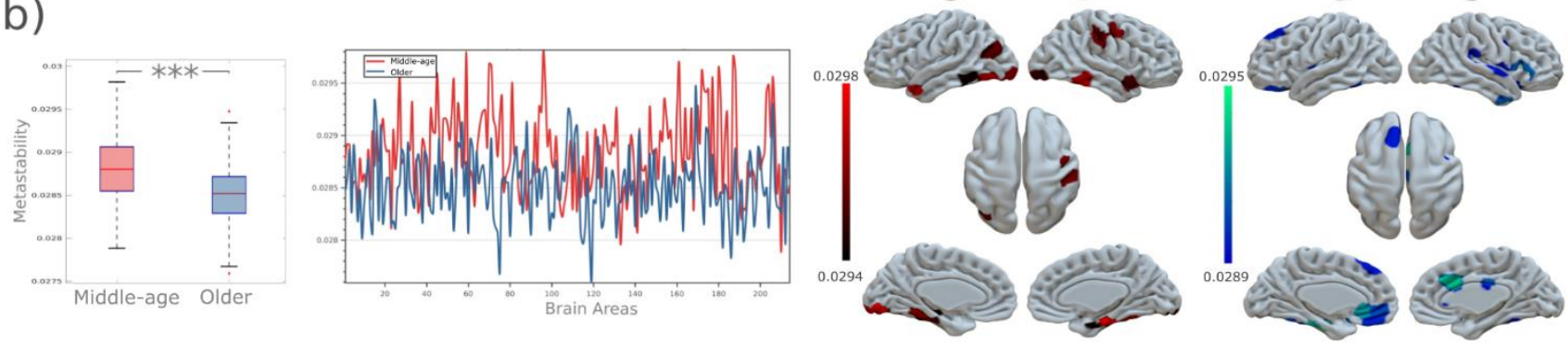

Figure 2: Intrinsic Ignition Framework. (a) Ignition measure. The boxplot shows the mean integration (ignition) for each group (middle-age group and older group). The ignition was higher in the older group (in blue) than in the middle-age group (in red) ( $<$ 0.001). The second graph shows ignition plotted across brain areas. Rendered brains represent the 20 regions with the highest ignition for each group (middle-age in red and older group in blue). (b) Metastability measure. By contrast, the middle-age group showed higher metastability across the whole-brain compared to the older group $(\mathrm{p}<0.001)$. P-values are based on Monte-Carlo permutation tests, $* * *$ represents $\mathrm{p}<0.001$. 
bioRxiv preprint doi: https://doi.org/10.1101/2020.06.29.164343; this version posted June 29, 2020. The copyright holder for this preprint (which was not certified by peer review) is the author/funder, who has granted bioRxiv a license to display the preprint in perpetuity. It is made available under aCC-BY-NC-ND 4.0 International license.

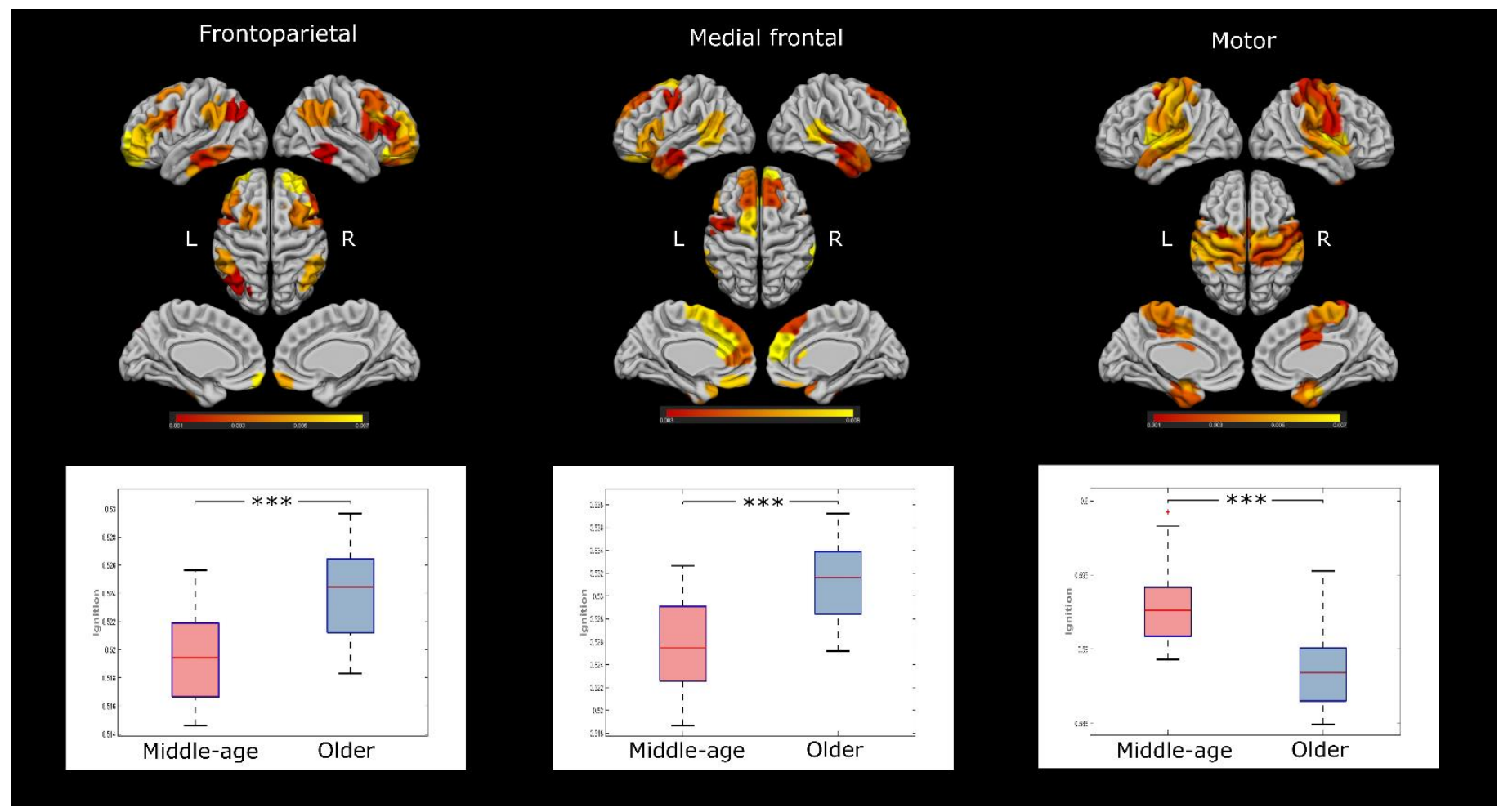

Figure 3: Differences in ignition across resting-state networks. The plots show the differences between groups in each significant resting-state network; rendered brains represent the absolute difference in ignition values for each brain area in each network between the middle-age and older groups (the greatest difference is marked in yellow). Compared to the middle-age group, intrinsic ignition was significantly higher in the older group in the frontoparietal network (FDR-corrected, p<0.001) and medial frontal network (FDR-corrected, p<0.001). By contrast, intrinsic ignition was significantly higher in the middle-age group in the motor network (FDR-corrected, $\mathrm{p}<0.001$ ). The default-mode, subcortical, visual I, visual II, and visual association networks were not significantly different between groups. 
bioRxiv preprint doi: https://doi.org/10.1101/2020.06.29.164343; this version posted June 29, 2020. The copyright holder for this preprint (which was not certified by peer review) is the author/funder, who has granted bioRxiv a license to display the preprint in perpetuity. It is made available under aCC-BY-NC-ND 4.0 International license.

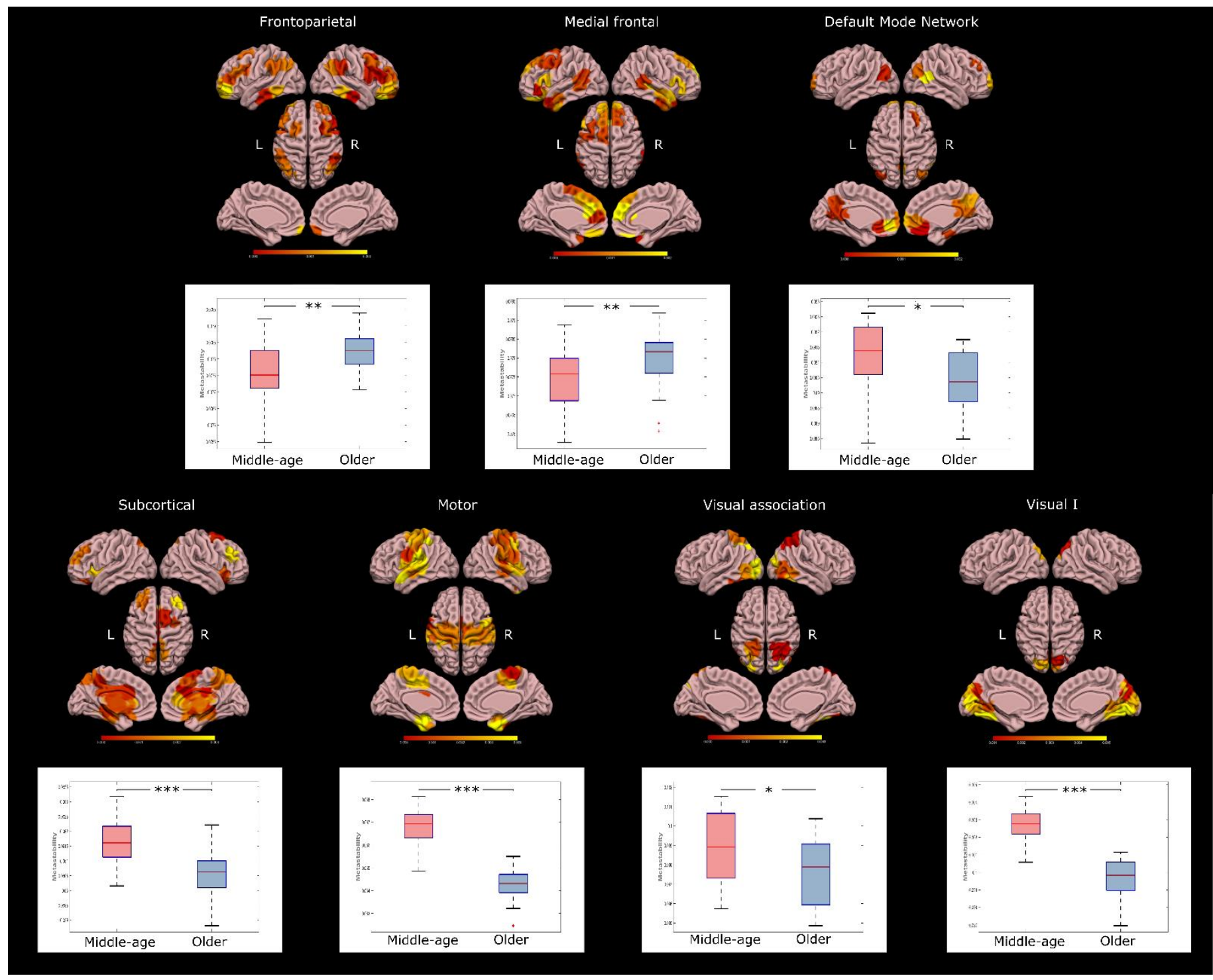

Figure 4: Differences in metastability across resting-state networks. The plots show the differences between groups in each significant resting-state network, whereas rendered brains represent the absolute difference (middle-age and older) between metastability values for each brain area in each network (in yellow the highest difference). The older group showed significantly increased metastability compared to the middle-age group in the frontoparietal network (FDR-corrected, p<0.01) and medial frontal network (FDR-corrected, $\mathrm{p}<0.01$ ), whereas the middle-age group showed increased metastability in the default-mode network (FDR-corrected, $\mathrm{p}<0.05$ ), subcortical network (FDR-corrected, $\mathrm{p}<0.001$ ), motor network (FDR-corrected, p<0.001), visual association network (FDR-corrected, $\mathrm{p}<0.05$ ), and visual I network (FDR-corrected, $\mathrm{p}<0.001$ ). 
bioRxiv preprint doi: https://doi.org/10.1101/2020.06.29.164343; this version posted June 29, 2020. The copyright holder for this preprint (which was not certified by peer review) is the author/funder, who has granted bioRxiv a license to display the preprint in perpetuity. It is made available under aCC-BY-NC-ND 4.0 International license.

a)

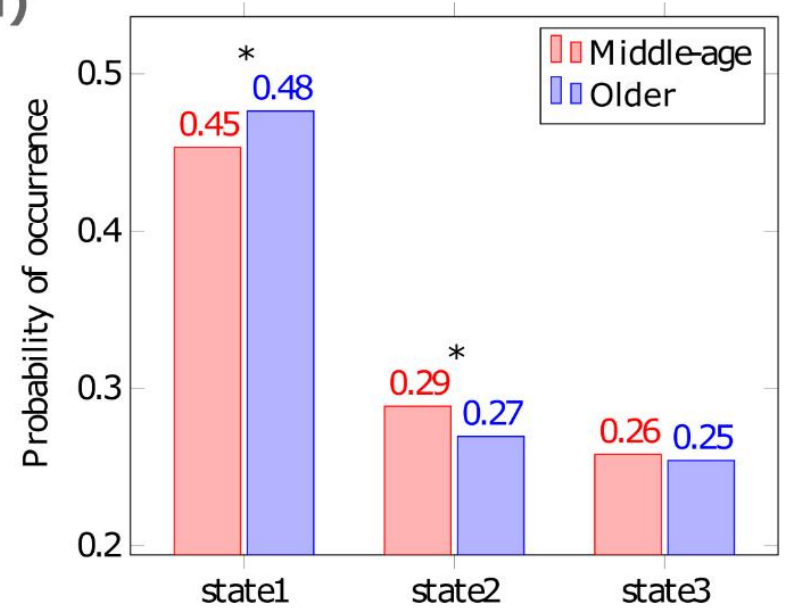

b)

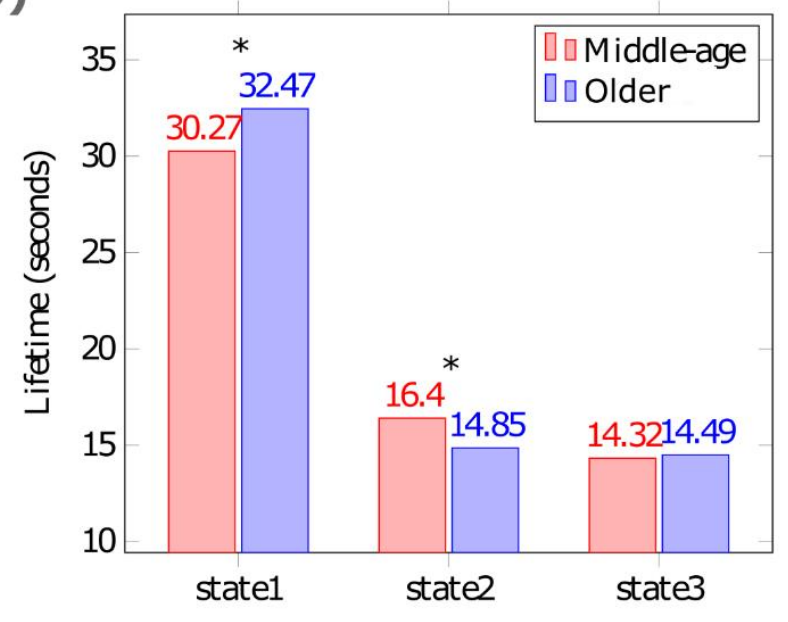

c)
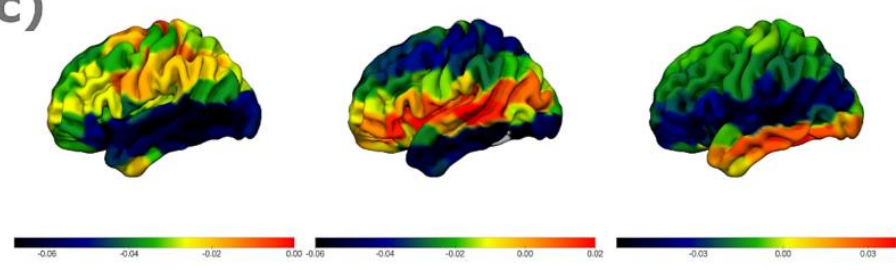

d)
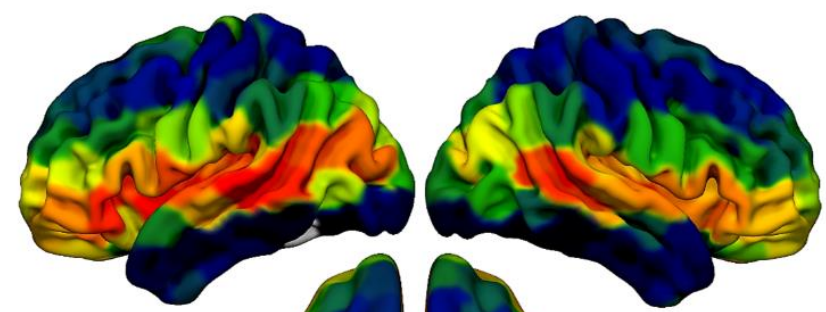

$\mathbf{R}$

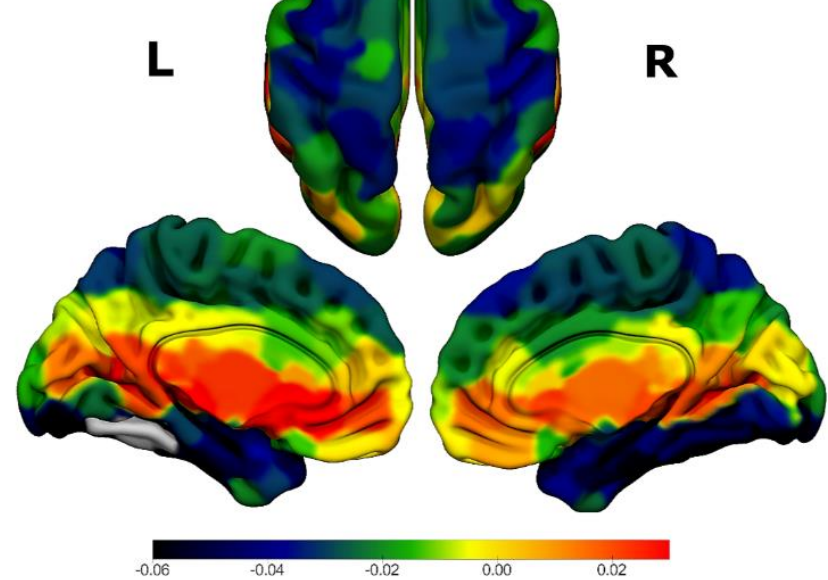

Figure 5: Metastable substates obtained by clustering. We identified three metastable substates that occurred frequently across all subjects during rest. The states are shown from higher to lower probability of occurrence. A) Differences in probability and B) differences in duration of each metastable substate between the middle-age group (in red) and the older group (in blue) during the resting-state scan. C) Metastable substates rendered on the cortex with Surfice. The first metastable substate had the highest probability of occurrence. This state was more likely to occur in subjects in the older group (mean, 0:476 \pm 0:008 (s.e.) vs.0:453 \pm 0:008 in the middle-age group, FDR-corrected $\mathrm{p}=0.03$ ); the duration of this state was also higher in the older group, although this comparison was no significant after FDR correction $(32: 465 \pm 0: 957 \mathrm{~s}$ vs. 30:265 \pm 0:791 in the middle-age group, $\mathrm{p}=0.04$, uncorrected). The second metastable substate is especially interesting because it overlaps with the rich club. The probability of this state occurring was higher in the middle-age group (mean 0:288 0:007 (s.e.) vs. 0:269 0:006 in the older group, FDR-corrected $\mathrm{p}=0.026$ ); the duration of this state was also higher in the middle-age group ( mean 16:399 $\pm 0: 605 \mathrm{~s}$ vs. 14:853 \pm 0:414 s in the older group, FDR-corrected $\mathrm{p}=0.01$ ). The third metastable substate was not significantly difference between groups in its probability of occurrence $(\mathrm{p}=0.35)$ or duration $(\mathrm{p}=0.39)$. D) Relevant metastable substate overlapping with rich-club regions in both hemispheres (the superior frontal cortex, precuneus, insula and subcortical areas such as the caudate, putamen, hippocampus, and thalamus). 